\title{
有机材料在潜指纹显现中的应用研究进展
}

\author{
金晓东*, $a$ 毕天博 ${ }^{a}$ 辛 然 $b$ 吴国萍 $a$ 徐同祥 $*, a$ 马荣梁 $*, c$
}

( ${ }^{a}$ 江苏警官学院刑事科学技术系 江苏省食品药品与环境犯罪技术检验工程实验室 南京 210031)

( ${ }^{b}$ 江苏省公安厅物证鉴定中心 南京 210012)

( ${ }^{c}$ 公安部物证鉴定中心 北京 100038)

\begin{abstract}
摘要 犯罪现场中所发现的最重要的物证之一的指纹可以直接认定人身，在侦查破案和法庭诉讼中发挥重要作用. 但 在实际案件中, 提取相关客体上的指纹时，这些指纹往往不能用肉眼直接观察到，故将其称之为 “潜指纹”。尽管潜指 纹显现技术已经有了较大的发展，但在无损、灵敏和高效检测等方面仍面临着诸多难题，其一定程度上阻碍了刑事技 术人员的后续指纹鉴定工作. 因此, 开发高选择性、高灵敏度和方便快捷的潜指纹显现材料或显现技术就显得意义重 大. 在查阅国内外相关研究成果的基础上, 简要回顾了目前广泛使用的传统有机材料, 并较为详细地综述了近十年来 新出现的有机苂光材料(如聚集诱导发光材料、共轭聚合物材料及其它有机苂光材料等)在潜指纹显现中的应用研究进 展，着重概述各相关有机材料的设计理念及显现潜指纹的机理，并对存在的问题进行讨论，展望有机材料在潜指纹显 现研究中的未来发展趋势.
\end{abstract}

关键词 潜指纹显现; 有机材料; 聚集诱导发光; 共轭聚合物; 法庭科学

\section{Advances in the Application of Organic Materials for the Development of Latent Fingerprints}

\author{
Jin, Xiaodong ${ }^{*, a}$ \\ $\mathrm{Bi}$ Tianbo ${ }^{a}$ \\ Xin, $\operatorname{Ran}^{b}$ \\ $\mathrm{Wu}, \mathrm{Guoping}^{a}$ \\ $\mathrm{Xu}$, Tongxiang ${ }^{*, a}$ \\ Ma, Rongliang*c \\ ( ${ }^{a}$ Department of Criminal Science and Technology \& Jiangsu Engineering Laboratory of Food, Drug, and Environment \\ Criminal Investigation and Forensic Analysis, Jiangsu Police Institute, Nanjing 210031) \\ $\left({ }^{b}\right.$ Center of Forensic Science and Technology, Bureau of Public Security for Jiangsu Province, Nanjing 210012) \\ ( ${ }^{c}$ Institute of Forensic Science, Ministry of Public Security, Beijing 100038)
}

\begin{abstract}
Fingerprint can directly identify the person, and it is one of the most important physical evidence in the criminal scene. Fingerprint has always been considered as the "head of physical evidence" and plays an important role in the investigation and court proceedings. However, the fingerprint on the relevant object can not be directly observed by human eyes in actual cases, so it is also called "latent fingerprint". Although the latent fingerprint development technology has made great progress, it still faces many difficulties in the aspects of nondestructive, sensitive and efficient. And, it will bring serious difficulties to the subsequent fingerprint identification work for the criminal technicians. Therefore, it is of great significance to develop highly selective, sensitive and convenient latent fingerprint developing materials or techniques. In view of this, on the basis of the research achievements at home and abroad, the application of traditional organic materials widely used in latent fingerprint development and the new fluorescent organic materials is briefly reviewed, such as aggregation induced emission materials, conjugated polymer materials and other organic fluorescent materials, in latent fingerprint development in recent ten years. The design concept of related organic materials and the mechanism of developing latent fingerprints are summarized. Finally, the existing problems are discussed, and the future development trend of organic materials in developing
\end{abstract}

\footnotetext{
* Corresponding authors. E-mail: jinxiaodong@jspi.edu.cn; xutongxiang@jspi.edu.cn; marl2013@163.com Received April 24, 2020; revised June 9, 2020; published online June 24, 2020.

Project supported by the Qing Lan Project of the Jiangsu Higher Education Institutions of China, the National Key R\&D Program of China (No. 2018YFC0807205), the Natural Science Foundation of Jiangsu Province (No. BK20191416), the Basic Research Fund Scheme to Strengthen Policing, Ministry of Public Security of China (No. 2019GABJC19), the High-level Introduction of Talent Scientific Research Start-up Fund (No. JSPI17GKZL402) of Jiangsu Police Institute.

江苏高校"青蓝工程"、国家重点研发计划(No. 2018YFC0807205)、江苏省自然科学基金(No. BK20191416)、公安部科技强警基础工作专项(No. 2019GABJC19)、江苏警官学院高层次引进人才科研启动费(No. JSPI17GKZL402)资助项目.
} 
latent fingerprints is prospected.

Keywords the development of latent fingerprint; organic material; aggregation-induced emission; conjugated polymer; forensic science

指纹可以直接认定人身, 被认为是在犯罪现场中发 现的最重要的物证之一, 有着 “物证之首” 的美誉, 在 侦查破案及法庭诉讼中发挥着重要作用. 近年来, 尽管 DNA 及电子物证等新型技术发展迅速, 但指纹鉴定仍 然是刑事技术人员侦查破案最重要的手段之一. 指纹鉴 定案件的数量通常与其他所有法医案件的数量之和相 当甚至超过它们, 譬如使用指纹证据破案的案件数量大 约是使用 DNA 的 10 倍 ${ }^{[1]}$.

指纹, 是指人类手指末端上的皮肤纹理, 由隆起的 乳突线花纹(或称之为 “摩擦揹线”) 和凹陷的小犁沟(或 称之为 “皱纹” ) 间隔分布所形成的复杂纹路图案 ${ }^{[2]}$. 这 种凹凸的纹路图案具有人皆有之、人各不同且终生不变 的特征. 由于人的皮肤表面含有汗液、油脂等物质，当 用手指触碰物体表面时, 这些物质会转移并沉积在物体 表面, 形成手指末端皮肤乳突线复杂纹路图案的接触印 痕. 我们在日常生活中遇到的大多数这种接触印痕被称 之为 “潜指纹 (latent fingerprints, LFPs)” 或 “潜手印 (latent fingermarks, LFMs)”, 这种接触印痕很难用肉眼 直接观察到. 因此, 它们需要一些特殊的处理方法使其 显现，以便后期进行进一步的个体认定. 能否有效地显 现潜指纹, 直接影响着相关案件是否能够被快速、准确 的侦破. 为此, 国内外许多科学家 (不仅仅是法庭科学 家 $^{[3-6]}$, 还有化学家 ${ }^{[7-9] 、}$ 物理学家 ${ }^{[10-11]}$ 和生物学家 ${ }^{[12-13]}$ 等)都在致力于开发新的潜指纹显现技术或显现材料用 于潜指纹的无损、快速的显现.

迄今为止, 已有多种传统的方法用于潜指纹的显 现, 根据其显现原理的不同, 主要可分为光学显现法 (如紫外光检验、激光检验等)、物理吸附法(如粉末刷显 法、碘熏法等)和化学显现法[如 $\mathrm{AgNO}_{3}$ 法、氰基丙烯酸 酯( “502” 胶)熏显技术、狮三酮法、1,8-二氮杂-9-芴酮 (DFO)法、粉末刷显法等]三大类 ${ }^{[5,14-19]}$. 这些传统的方法 在一定程度上满足了办案人员对潜指纹显现的需求, 但 随着在对比度、无损检测、灵敏度等方面要求的提高及 潜指纹残留物(如爆炸物、药物代谢物等)的检测需要, 这些传统的潜指纹显现材料或技术已不能满足实际要 求. 这也迫使着科研人员去开发新的材料或新的技术, 以适应时代的发展.

无机荧光纳米材料 [如量子点 (quantum dots, QDs) ${ }^{[20-21]}$ 、稀土上转换苂光纳米材料(rare earth upconversion fluorescent nanomaterials, $\mathrm{UCNMs})^{[22]}$ 、有机苂光 材料 [如聚集诱导发光 (aggregation-induced emission,

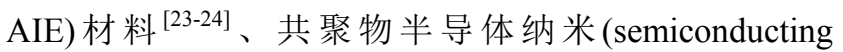

polymer dots, Pdots)材料 ${ }^{[25]}$ 、有机一无机杂化材料 ${ }^{[26]}$ 等]、

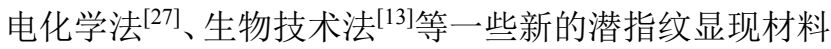
或技术为满足办案人员的需要而出现. 国内外已有不少 关于潜指纹显现研究的综述 ${ }^{[1,2,28-37]}$, 但鲜见专门的系统 介绍有机苂光材料在潜指纹显现应用研究的综述.

有机苂光材料通常是含有 $\pi$ 共轭体系的芳香性有机 分子, 通过合理的分子设计, 可使其展现出良好的光学 性能. 由于有机荧光材料具有结构组成多样化及性能调 节空间大的特点，已被广泛用于生物检测、疾病诊疗和 发光二极管等领域. 有机荧光材料在上述多个领域所展 现出的突出优势给潜指纹显现的研究工作开辟了一个 新的方向. 众多科研工作者致力于新型有机苂光材料的 构建，并将其与传统的潜指纹显现方法(如粉末刷显法、 溶液浸泡法、“502” 胶熏显后染色法等)相结合, 实现对 潜指纹高效、灵敏的显现. 本文将在国内外研究成果的 基础上，简要回顾了目前广泛使用的传统有机材料，并 较为详细地综述了近十年来新出现的有机苂光材料在 潜指纹显现中的应用研究进展, 着重概述各相关有机材 料的设计理念及显现潜指纹的机理, 并对存在的问题进 行讨论, 展望有机材料在潜指纹显现研究中的未来发展 趋势.

\section{1 传统潜指纹显现技术中的有机材料}

\section{1 氭基丙烯酸酯(“502”胶)}

氰基丙烯酸酯熏显法，又称为 “502” 胶熏显或 “超 级胶” 熏显, 它是广泛用的潜指纹显现技术之一, 尤其 适用于非多孔客体上潜指纹的显现，如塑料、玻璃和金 属等. “502”胶的有效成分 $\alpha$-氧基丙烯酸乙酯，在指纹 残留物(如水和弱碱等)的引发下，与客体上潜指纹相结 合，迅速聚合形成白色多孔聚合物，原位固定指纹于客 体表面，避免了指纹细节结构的缺失 ${ }^{[38]}$. 但使用该技术 显现潜指纹时，需要控制单体 $\alpha$-氰基丙烯酸乙酯的熏显 时间和用量, 避免过度熏显, 影响成像质量. 此外, 利 用该技术显现潜指纹时，得到的潜指纹图像往往缺少对 比度, 尤其是作用在浅色客体上 ${ }^{[39]}$. 为解决这一症结, 科研工作者开发出了苂光(或彩色) “502” 胶熏显潜指 纹 ${ }^{[00]}$. 但从实战出发，“502”胶熏显技术协同指纹粉染 色法是目前最为广泛使用的二次增强处理方法之一 ${ }^{[41]}$, 特别是使用苂光材料(如罗丹明 $6 \mathrm{G}^{[42]}$ 等)染色熏显后的 指纹，能有效提高潜指纹成像的对比度和显现质量. 尽 管“502”胶熏显技术用于潜指纹显现时，有着诸多优点， 但也不能忽视 “ 502 ” 胶熏显技术在健康和安全等方面 
的问题，如 “502” 胶加热后，所产生的蒸汽会对人体的 皮肤、眼睛及黏膜造成极大损害等.

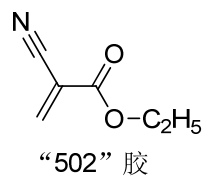

\section{2 狮三酮}

狮三酮(ninhydrin)显现法是目前用于渗透性客体 (如纸张、原木)上潜指纹显现的一种最常见的方法. 早 在 1910 年, 狮三酮就已被人工合成出来, 且最初是用于 检测生物样品中是否含有蛋白质或胺类化合物, 并未在 法庭科学领域得到应用 ${ }^{[43]}$. 直到 20 世纪中期, 狮三酮 显现渗透性客体上潜指纹的性能才由 Hofsten 报道 ${ }^{[17]}$, 这也彻底改变了当时渗透性客体(主要指的是纸张)上潜 指纹无法处理的难题. 狮三酮之所以能够显现潜指纹, 主要是由于指纹残留物中的氨基酸与苑三酮发生了显 色反应, 生成了复杂的蓝紫色化合物(鲁赫曼紫, Ruhemann's purple). 对于鲁赫曼紫形成的机理, 科学家们争 论了近 90 年. 目前, 普遍被世人所认可的机理是由 Friedman 和 Williams 所提出 ${ }^{[44-45]}$, 主要包含如下四个过 程(Scheme 1): (i)狮三酮在水合型(1)与三酮型(2)之间的 转化达到动态平衡状态; (ii) 氨基酸中的氨基亲核进攻 2 结构中的 $\beta$-羊基生成席夫碱 3,3 经过脱羧形成 1,3-偶极 共振结构 (4 和 5), 并通过质子转移得到中间体醛亚胺 $\mathbf{6}$; (iii) 6 在酸性条件下水解, 生成醛和 2-氨基-1,3-苑满二 酮(7); (iv) 7 与另一分子 1 发生缩合反应生成鲁赫曼
紫 (8 和 9, 二者处于动态平衡状态). 这也为狮三酮显现 渗透性客体上的潜指纹奠定了理论基础. 虽然狮三酮法 在显现渗透性客体上的潜指纹的应用中有着显著的优 点, 但该方法往往操作较为复杂, 需要严格控制实验条 件，理想的 $\mathrm{pH}$ 条件为 $4.5 \sim 5.2$, 湿度需控制在 $50 \%$ $80 \%$ 且置于温热的环境中等. 最为关键的是，狮三酮法 显现潜指纹时，理想实验条件的确定往往需要技术人员 具备较为娴熟的技能及经验，这也直接影响着潜指纹的 显现效果.

\subsection{1,8-二氮杂-9-芴酮}

针对狮三酮法存在的不足, 法庭科学家根据狮三唒 法显现潜指纹的原理，开发设计了许多结构相似的化合 物 ${ }^{[46-49]}$. 但经研究发现, 1,8-二氮杂-9-芴酮(DFO)是其中 最为突出且能够满足实战需求的一种理想荧光试剂. 该 化合物在 380 450 nm 波长的光源激发下，可发出较强 的荧光，灵敏度较高. DFO 与狮三酮都属于酮类化合物， 其显现潜指纹的机理与狮三酮类似，都是与指纹残留物 中的氨基酸发生显色反应 ${ }^{[50]}$. 具体反应机理如下 (Scheme 2): (i)氨基酸中的氨基亲核进攻 DFO 分子中的 羰基生成席夫碱 10, 并经过脱羧形成醛亚胺 11; (ii) 11 在酸性条件下水解, 生成醛和芳香胺 12; (iii) 12 与另一 分子 $\mathrm{DFO}$ 发生缩合反应生成浅紫色产物 13(在蓝绿色光 源的激发下有较强的橙色荧光). 与狮三酮法不一样的 是, DFO 法显现潜指纹时, 需要在高温、低湿环境下进 行, 且在室温下无需后处理操作就可以实现对潜指纹的 荧光显现. 但在实战操作中，技术人员往往将 DFO 法与<smiles>[R]C(NCC1(O)C(=O)c2ccccc2C1=O)C(=O)NC1(O)C(=O)c2ccccc2C1=O</smiles>
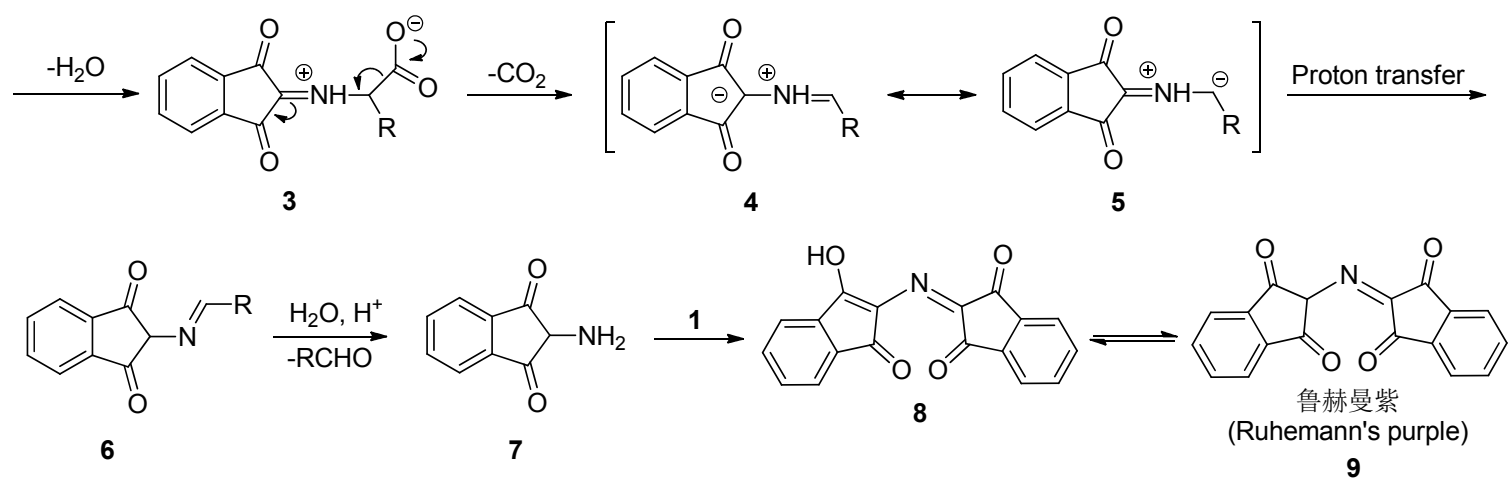

图式 1 狮三酮对氨基酸的响应机理

Scheme 1 Response mechanism of ninhydrin to amino acids 


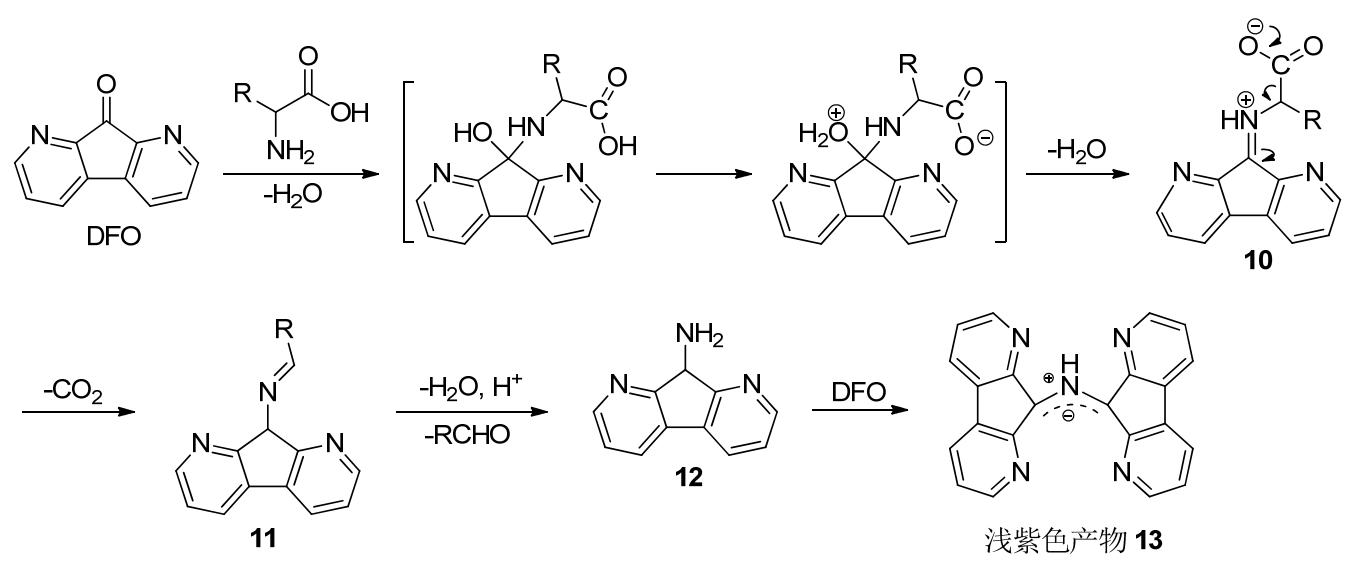

图式 2 DFO 对氨基酸的响应机理

Scheme 2 Response mechanism of DFO to amino acids

狮三酮法协同使用，即将渗透性客体上的潜指纹用 DFO 处理后, 再用狮三酮处理, 以进一步改善潜指纹的 成像质量 ${ }^{[31]}$. 这主要是由于 DFO 不能够完全的与指纹 残留物中的氨基酸发生反应, 导致残留的氨基酸与荫三 酮发生显色反应所致. 这种协同显现潜指纹的方法, 相 比于单一的使用 DFO 法或狮三酮法而言, 具有更高的 灵敏度. 当然, DFO 的毒性与致癌问题也不能够被忽略, 这也是该法显现潜指纹所面临的一个问题.

\section{4 粉末刷显法中的传统有机苂光染料}

粉末刷显潜指纹技术是一种最为古老和应用最为 广泛的潜指纹显现方法 ${ }^{[14]}$, 至今, 其仍然是犯罪现场中 显现潜指纹的最重要和最有效的方法之一. 许多优良的 粉末或者纳米粉末被制备出来, 如磁性粉、 $\mathrm{SiO}_{2} 、 \mathrm{TiO}_{2}$ 和铝粉等, 它们通过吸附作用与潜指纹纹线上的油脂发 生作用, 实现对潜指纹的显现. 但这些粉末仅适用于那 些背景与粉末本身色差较大的客体上潜指纹的显现. 因 此, 为了解决这一突出的问题, 科研人员尝试将苂光粉 末用于潜指纹的显现. 1977 年, Dalrymple、Menzel 和 Duff $^{[11]}$ 首次提出将苂光染料香豆素-6 (14)协同氩离子激 光用于潜指纹的显现, 这开创了苂光染料在潜指纹显现 研究领域的先河. 随后, 罗丹明 B (15)和罗丹明 6G (16) 等传统苂光染料陆续被报道用于潜指纹的显现研究, 这 些苂光染料用于潜指纹显现时, 往往具有更好的分辨率 和更高的信噪比. 然而, 这些传统的苂光染料在显现潜 指纹时, 仍存在一些缺陷, 如在聚集态或固态时, 它们 的荧光很弱或没有荧光, 这也就是所谓的聚集诱导猝灭 效应(aggregation-caused quenching, ACQ). 具体到潜指 纹显现的应用时, 就是潜指纹成像图像的荧光强度较 弱, 导致显现质量较差. 因此, 科研人员开发出了许多 性能优良的新型有机发光材料用于潜指纹的显现, 如 AIE 材料和 Pdots 材料等.

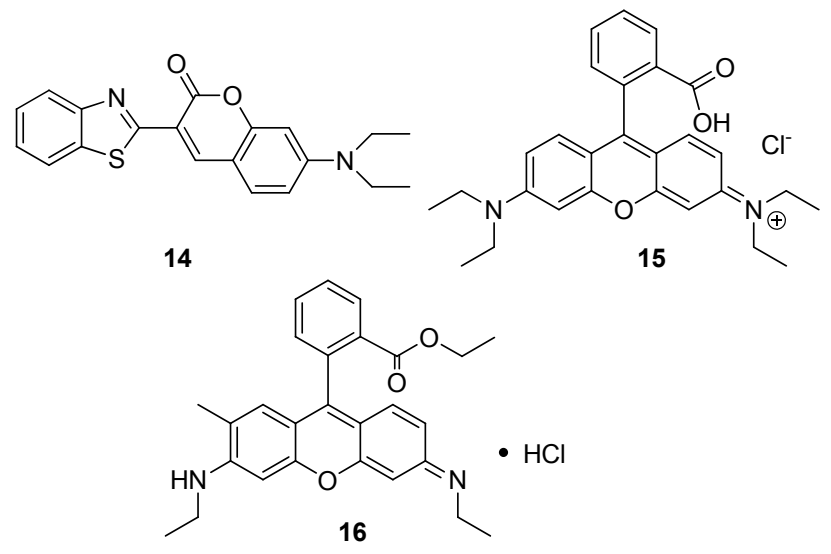

\section{2 小分子 AIE 有机材料在潜指纹显现中的应用 研究}

基于 1-甲基-1,2,3,4,5-五苯基噻咯(17)分子在良溶剂 中苂光很弱, 而在聚集态时有着很强的苂光这一特殊现 象, 唐本忠课题组 ${ }^{[11]}$ 于 2001 年, 提出了 AIE 的概念, 这 引起了众多学者的关注. 近年来, 科学家们利用 AIE 分 子的特性, 不断地探索其在不同领域中的应用, 如法庭 科学 ${ }^{[52-53]}$ 、化学传感 ${ }^{[54-56]}$ 和疾病诊疗 ${ }^{[57]}$ 领域等.

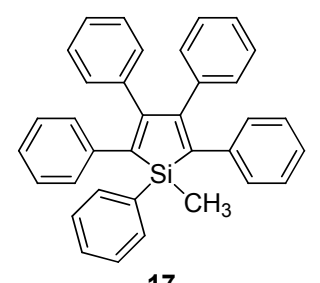

17

\section{1 基于单一 AIE 分子显现潜指纹的研究进展}

将 AIE 分子用于法庭科学领域潜指纹的显现是一 个崭新的研究热点, 国内外多个课题组都进行了相关研 究. 2012 年, 苏涁课题组 ${ }^{[23]}$ 首次报道了利用四苯乙烯 
(18)显现潜指纹, 开创了 AIE 技术用于潜指纹显现研究 的先河. AIE 技术显现潜指纹的机理是疏水一疏水吸附作 用，即 18 在水溶液中所形成的纳米颗粒是疏水性的，而 潜指纹残留物中的油性物质也呈现出疏水性, 二者之间 通过疏水一疏水吸附作用, 将 18 所形成的纳米颗粒吸附 于潜指纹的纹线中, 从而在紫外灯的激发下, 实现对潜 指纹的苂光显现(图 1). 随后, 为了进一步探究该技术显 现潜指纹的机理, 他们利用亲疏水性不同的两个 AIE 分 子 ${ }^{58}$, 即含有亲水性基团羧基的 1-甲基-2-羧基苯乙烯 基-3,4,5,6-四苯基硅杂环戊二烯(19)和不含亲水性基团 的六苯基硅杂环戊二烯(20), 显现潜指纹时, 发现不含 亲水性基团 $\mathrm{COOH}$ 的 $\mathrm{AIE}$ 分子 $\mathbf{2 0}$ 相比于含有亲水性基 团 $\mathrm{COOH}$ 的 $\mathrm{AIE}$ 分子 19, 潜指纹显现效果要好, 这也证 实了 AIE 技术显现潜指纹的机理是通过疏水-疏水吸附 作用实现的.
我们也报道了几种用于潜指纹显现的 AIE 分 子 ${ }^{[24,53,59]}$, 都可以较好地显现多种客体上的潜指纹. 考 虑到用于潜指纹显现研究的 $\mathrm{AIE}$ 分子 $(\mathbf{1 8} \sim \mathbf{2 0}$, 图 2)数 量有限, 并且所报道的用于潜指纹显现的 AIE 分子的激

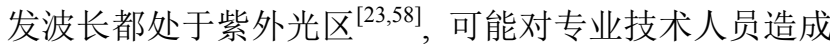
光学伤害. 我们 ${ }^{[24]}$ 于 2015 年报道了一例处于可见光区 激发、红光区发射的苂光探针 21 用于多种客体上潜指 纹的显现，并通过固态荧光光谱研究了其显现潜指纹的 机理. 随后, 为了进一步探讨亲(疏)水链基基团存在与 否的影响, 本课题组 ${ }^{[53]}$ 构建了一例含有长疏水链基的 四苯乙烯衍生物 22, 并用于多种客体上潜指纹的高效 显现，且通过自动指纹识别系统(Automated Fingerprint Identification System, AFIS), 将潜指纹显现图像与标准 参照指纹进行匹配, 取得了较为积极的效果. 这也表明, 探针 22 具有潜在运用于案件现场潜指纹显现的可能.

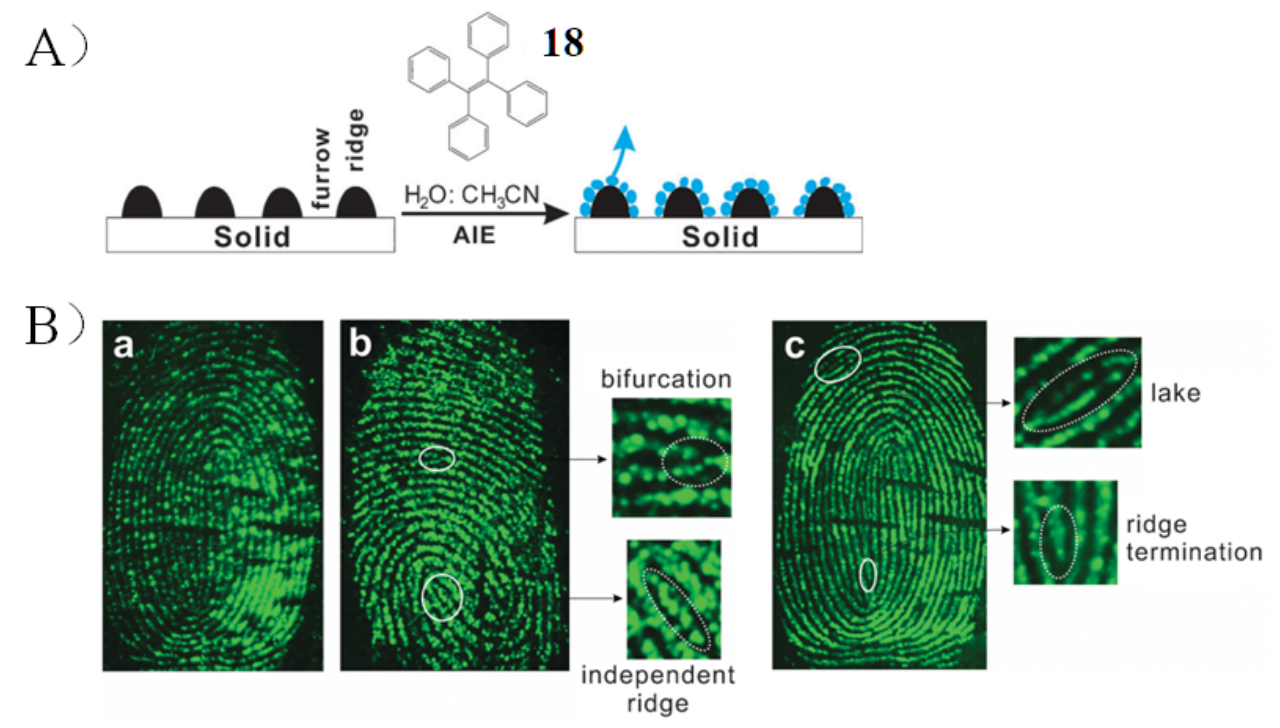

图 1 (A)基于 AIE 分子 18 显现潜指纹的原理图和(B) 18 显现不同客体上潜指纹的苂光成像图 ${ }^{[23]}$

Figure 1 (A) Schematic illustration of fingerprint enhancement by AIE of 18 and (B) fluorescence images of latent fingerprints developed by 18 on different substrates

Conditions: 18 concentration: $0.25 \mathrm{mmol} / \mathrm{L}, \lambda_{\mathrm{ex}}=365 \mathrm{~nm}$, the water fraction was $50 \%$ (volume fraction) (a: glass), $40 \%$ (volume fraction) (b: stainless steel sheet) and $40 \%$ (volume fraction) (c: aluminium foil), respectively

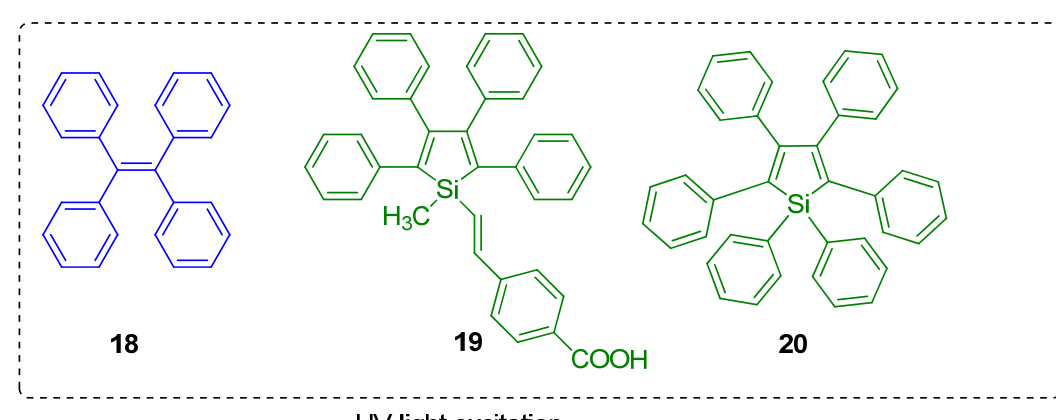

UV light excitation

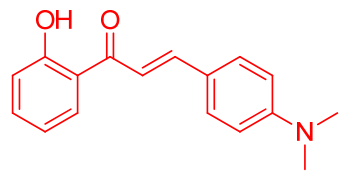

21

Visible light excitation

图 2 染料 $18 \sim 21$ 的化学结构

Figure 2 Structures of dyes $\mathbf{1 8} \sim \mathbf{2 1}$ 


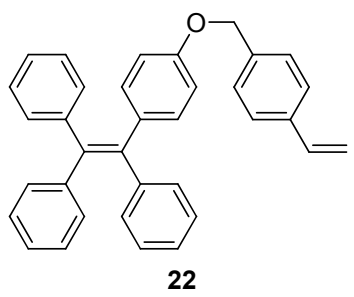

Singh 课题组 ${ }^{[60]}$ 合成了两例基于二苯基嘧啶酮-亚 水杨基胺的 $\mathrm{AIE}$ 分子 $\mathbf{2 3}$ 和 $\mathbf{2 4 . 2 3}$ 和 24 在纯 $\mathrm{CH}_{3} \mathrm{CN}$ 溶 液里呈现出弱的激发态分子内质子转移 (excited state intramolecular proton transfer, ESIPT)苂光发射( $\mathrm{N}$ 型发 射)峰, 而在含水量高于 $70 \%$ (体积分数)时, 两例分子在 溶液里随着纳米颗粒的析出, ESIPT 效应得到恢复, 并 分别在 526 和 $518 \mathrm{~nm}$ 处呈现出强的 ESIPT 绿色荧光(T 型发射). 这些性质表明, 23 和 24 具有典型的 AIE 性质. 为了研究 23 和 24 分子中 ESIPT 效应对荧光增强方面的 影响, 他们合成了化合物 25 (不具有 ESIPT 效应). 实验 表明, 化合物 25 不具有典型的 AIE 性质, 这也说明了 23 和 24 分子中 ESIPT 效应的存在, 对它们的 AIE 性质 起着决定性的作用. 随后, 他们将 AIE 分子 23、24 用于 铝板、钢板和玻璃三种客体上的潜指纹显现, 可观察到 指纹的二级结构.<smiles>CN(C)c1nc(-c2ccccc2)n(-c2ccccc2)c(=O)c1/N=C/c1ccccc1O</smiles>

23

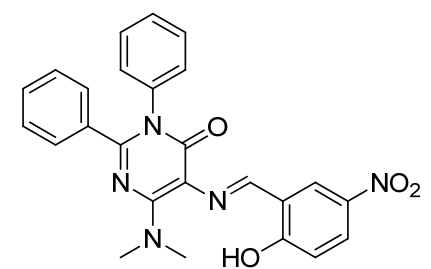

24<smiles>COc1ccccc1/C=N/c1c(N(C)C)nc(-c2ccccc2)n(-c2ccccc2)c1=O</smiles>

25

基于前期在 AIE \& ESIPT 分子显现潜指纹方面的 应用研究, Singh 课题组 ${ }^{[61]}$ 对化合物 23 进行结构上的改 变, 期望得到在光物理性质和在溶液里微观形态不一样 的分子. 因此, 他们合成了化合物 $\mathbf{2 6}$, 其发射波长从绿 光发射(化合物 23 的最大发射波长 $\lambda_{\mathrm{em}}=526 \mathrm{~nm}$ )红移至 红光发射(化合物 26 的最大发射波长 $\lambda_{\mathrm{em}}=564 \mathrm{~nm}$ ). 通 过动态苂光散射和扫描电镜证实了化合物 26 在含水量 为 $90 \%$ (体积分数)的乙腈水溶液中的结构为棒状结构 (化合物 23 为珊瑚礁结构). 随后研究了化合物 $\mathbf{2 6}$ 的 AIE 性质，并将其用于铝板、钢板和金属硬币上潜指纹的显
现，指纹的一级、二级结构可被清楚的观察到。<smiles>O=c1c(/N=C/c2ccccc2O)cnc(-c2ccccc2)n1-c1ccccc1</smiles>

26

考虑到目前文献中所报道的用于潜指纹显现的 AIE 分子都是纯有机小分子, 且开发具有高量子发光效率和 多重刺激响应的 AIE 分子用于潜指纹的显现是一个难 题, 朱红军和刘睿课题组 ${ }^{[62]}$ 报道了一例基于铱(III)的金 属有机配合物 27.27 有两个发射峰 $\left(\lambda_{\mathrm{em}, 1}=362 \mathrm{~nm}\right.$ 、 $\lambda_{\mathrm{em}, 2}=494 \mathrm{~nm}$ ), 在人眼较为敏感的光区一一绿光区发 射. 此外, 27 具有较高的苂光量子发光效率, 且呈现聚 集诱导磷光发光特性 (aggregation-induced phosphorescent emission, AIPE). 将 $\mathbf{2 7}$ 用于显现多孔或非多孔客体 上的潜指纹时，指纹的二级结构乃至三级结构都可以清 晰地观察到，且显现时间只需 $5 \mathrm{~min}$.

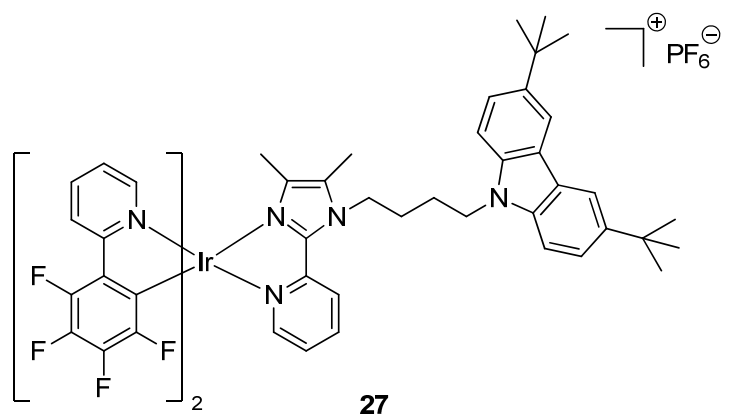

随后，该课题组 ${ }^{[63]}$ 又报道了三个基于铱(III)配合物 的金属有机化合物 $28 \sim 30$, 通过改变 $\mathrm{N}^{\wedge} \mathrm{N}$ 配体, 探讨了 它们的光物理性质.三例铱(III)配合物呈现出颜色可调 的固态苂光(绿 $\rightarrow$ 黄 $\rightarrow$ 橙黄), 且都具有 AIPE 效应. 在该 课题组此前成功地将具有 AIPE 效应的金属铱(III)配合 物 27 用于潜指纹的显现研究的基础上，他们改进了潜 指纹的显现方法，将这三例 AIPE 分子制备成乙醇/水 $(V: V=1: 9)$ 溶液, 实现了对多种客体上新鲜潜指纹、 残缺指纹和陈旧指纹的喷酒显现(图 3). 指纹的二级乃 至三级结构都可以被观察到, 且显现时间只需 $1 \mathrm{~min}$. 通过扫描电子显微镜(SEM) 对潜指纹成像前后的观察 (以化合物 28 为例), 指纹的纹线与小犁沟在成像前后都 可以清晰地被观察到. 这表明, 这种显现方法并不会造 成潜指纹细节结构的损坏. 此外, 通过 X 射线能谱仪 (EDS)分析，在成像后的指纹里可以观察到 Ir、S、F 和 $\mathrm{N}$ 新峰的出现，这也说明铱配合物与潜指纹中的油性物 质有着强烈的疏水一疏水作用。 

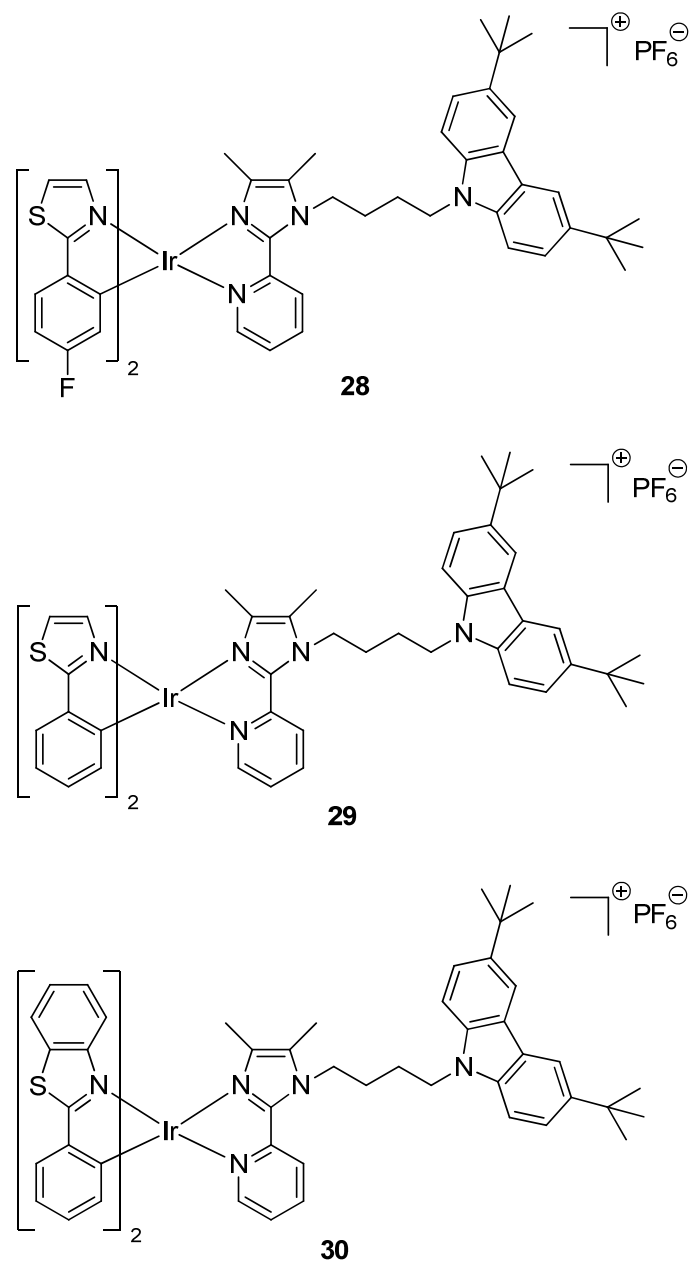

鉴于传统染料的 ACQ 效应, 唐本忠课题组 ${ }^{[64]}$ 基于 四苯乙烯合成了三例 $\mathrm{AIE}$ 分子 31 33, 并将磁性粉与这 三例 AIE 分子分别进行混匀后, 用于潜指纹的刷显. 从 荧光强度、分辨率及吸附性等方面看, 33 与磁性粉混匀 的粉末具有较好的效果. 随后, 他们将该混合粉末用于 多种多孔和非多孔客体上潜指纹的刷显, 所得到的苂光 增强的指纹图像的细节结构清晰.<smiles>[R]c1ccc(C(=C(c2ccc([R])cc2)c2ccc([R])cc2)c2ccc([R])cc2)cc1</smiles><smiles>[R1]=[R]=C=[R]=[W]=[W]</smiles><smiles>[R]=[R]=C=[R]=CC=CN(c1ccccc1)c1ccccc1</smiles>

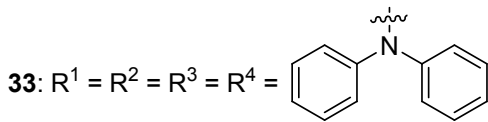

(A)

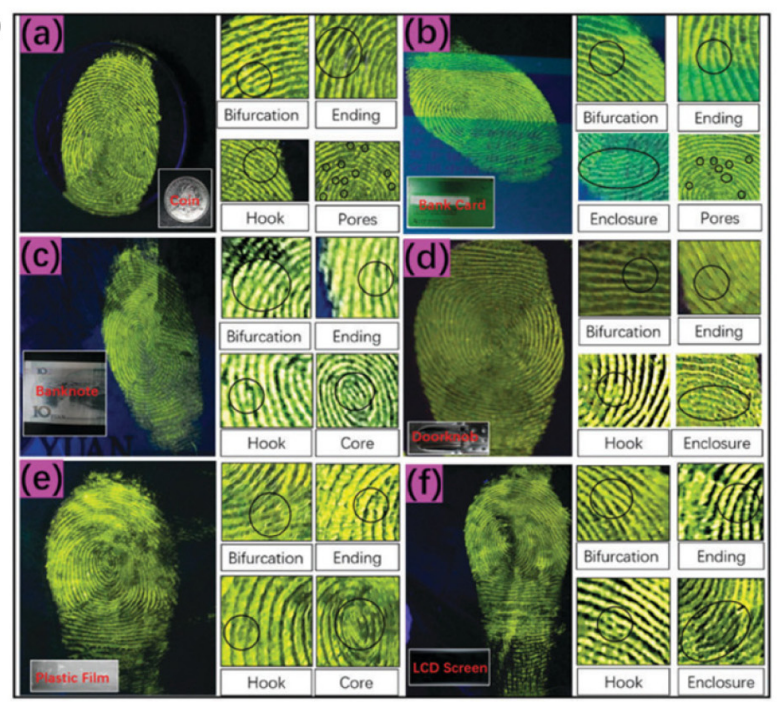

(B)

(C)
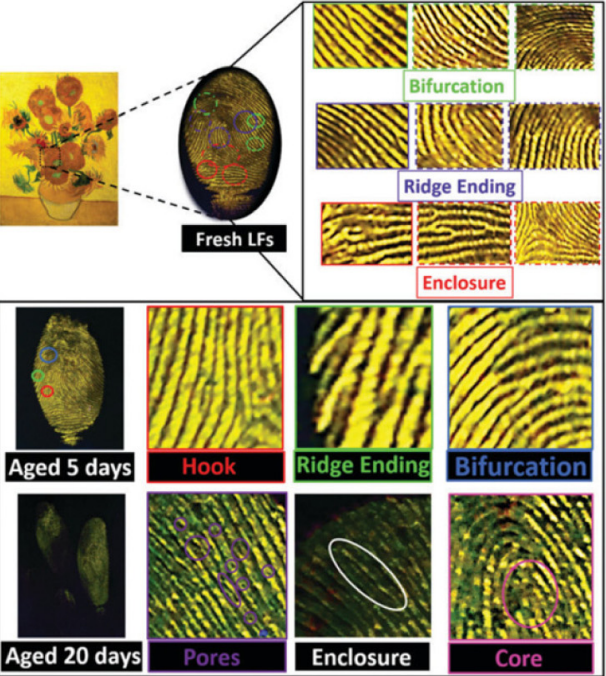

图 3 乙醇-水溶液 $(V: V=1: 9)$ 中, (A)染料 28 对不同客体上 新鲜潜指纹、染料 30 对纸张客体上的 $(\mathrm{B})$ 新鲜和 $(\mathrm{C})$ 陈旧 $(5 \mathrm{~d})$ 潜指纹、(D)染料 29 对纸张客体上的陈旧 $(20 \mathrm{~d})$ 潜指纹的喷酒 显现 ${ }^{[63]}$

Figure 3 Fluorescence images of (A) the fresh LFPs on different substrates developed by dye 28, (B) the fresh LFPs and (C) the old LFP ( 5 d) on paper developed by dye 30, and (D) the old LFP (20 d) on paper developed by dye 29 in ethanol-water ( $V$ : $V=1: 9)$ solution through spraying technology

众所周知，犯罪现场中的血渍包含了多种有效的信 息，可指导刑事技术人员进行犯罪调查，如根据犯罪现 场中血渍可发现可疑人员的 DNA; 根据血迹喷溅形态 可为犯罪现场的重建提供坚实的基础等. 此外，血潜指 纹往往也是凶杀现场最有可能碰到的物证，其能否成功 的显现对于案件的侦破及保护受害者具有重要的司法 实践作用. 尽管目前已有一些显现血渍(包括血潜指纹) 方法, 如酚酞和 3,3',5,5'-四甲基联苯胺(TMB)等，但这 些传统的血渍(包括血潜指纹)显现试剂的灵敏度及对比 
度较低, 这也迫使科研人员去开发新的显现技术用于犯 罪现场中血渍(包括血潜指纹)的高灵敏度、快速检测. 2019 年, 唐本忠课题组 ${ }^{[8]}$ 基于四苯乙烯构建了一例苂光 探针 34, 该探针分子结构中含有马来酰亚胺结构, 其可 以与血清白蛋白发生 “点击” 反应, 释放出游离的苂光 体 35, 实现苂光的 “turn-on” (图 4). 这种血渍的显现方 法条件温和, 无需催化剂就可以进行. 同时, 这也为保 护血渍中的 DNA 免遭破坏和揭示血迹的喷溅形态提供 了一种有效的方法. 此外, 通过血渍的喷浌轨迹和对血. 潜指纹的转移显现应用, 这种血渍显现方法要优于基于 鲁米诺发光的基准测试技术, 有用于犯罪现场中血迹可 视化的潜力.

最近，鉴于之前文献中已报道的用于潜指纹显现的 AIE 分子存在以下几个问题: (1) 它们的荧光为 “on-on” 模式, 需要用水洗或气吹对显现后的潜指纹进行后处 理, 去除多余的染料, 以避免残余的染料影响潜指纹的 成像质量; (2)这些 AIE 分子基本是用 $365 \mathrm{~nm}$ 的光源激 发, 可能会对人体造成光学伤害; (3)对客体的选择性较 差, 并且往往不能实现对指纹三级结构的高对比度和高 分辨率的显现. 李冲与朱明强等 ${ }^{[65]}$ 开发了一例新型的 用于潜指纹可视化的 AIE 分子 36 . 探针 $\mathbf{3 6}$ 通过三苯胺 和吡啶盐发生缩合反应, 形成 “推-拉” 电子结构. 三苯 胺基团是优良的供电子基团, 为探针 $\mathbf{3 6}$ 的疏水端; 而吡 啶基阳离子基团具有很强的吸电子性能, 为 $\mathbf{3 6}$ 的亲水 端. 由于吡啶基阳离子基团的存在，探针 36 具有较好的 水溶性(无需任何有机助溶剂就可以溶于水中), 因此其
在纯水中没有荧光，而在其水溶液中加入不良溶剂时， 其发生了聚集, 产生了强的红色苂光. 36 的纯水溶液作 用于客体上的潜指纹后，在 $405 \mathrm{~nm}$ 波长的光激发下，可 实现对多种客体(包括粗粘表面, 如墙面、砖块和纸张) 上潜指纹的浸泡或喷酒显现(图 5), 数秒内就可观察到 指纹轮廓, 且 $30 \mathrm{~s}$ 内就能形成具有高对比度和高分辨率 的清晰指纹成像图像. 此外, 与已报道的用于潜指纹显 现的 AIE 分子相比, $\mathbf{3 6}$ 无需额外的后处理(如用水洗或 气吹)就可以实现对潜指纹 “off-on” 显现. 最后，他们 通过苂光显微镜清楚地观察到指纹纹线的宽度及汗腺 孔径等指纹的三级特征(图 6), 甚至利用超分辨显微成 像技术, 获得了超过指纹三级结构的 $50 \mathrm{~nm}$ 以下光学分 辨率的纳米级细节, 这在潜指纹显现领域里尚属首次. 这些特点有利于对犯罪现场中潜指纹的采集, 且用户体 验和指纹的保真度较高, 可为法医学中建立可靠的指纹 采集标准化程序提供替代方案.

\section{2 基于 “502” 胶熏显技术协同 AIE 技术显现潜指纹 的研究进展}

“502” 胶熏显技术协同指纹粉染色法是目前最为广 泛使用的二次增强处理方法之一. 鉴于 AIE 技术在潜指 纹显现中有着显著的优势, 李钰皓等 ${ }^{[66]}$ 报道了一例聚 集增强发光(aggregation-enhanced emission, AEE)的荧光 探针 37, 并协同 “502” 胶熏显技术用于潜指纹的显现， 探针 37 以芴 ( $\pi$ 共轭)为苂光母核, 用 1,8 -芸酰亚胺(吸电 子基团)和葱(供电子基团)对苂光母体进行结构修饰, 形 成“推-拉”电子结构. 研究表明, 随着含水量的增加, 探

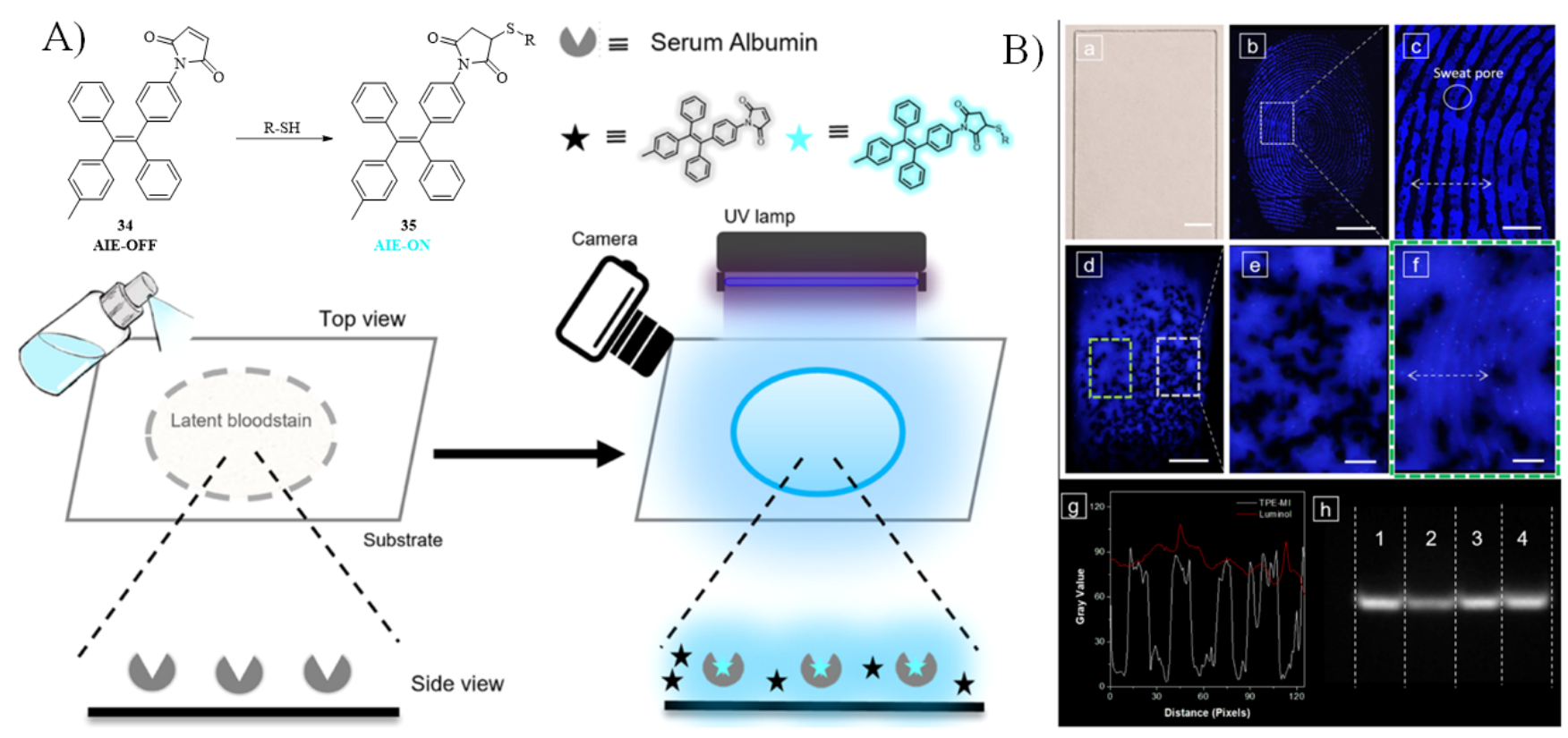

图 4 (A)染料 $\mathbf{3 4}$ 与血渍的反应机理及操作步骤和(B)利用染料 $\mathbf{3 4}$ 溶液对模拟犯罪现场中玻璃客体上血潜指纹的提取 ${ }^{[8]}$

Figure 4 (A) Mechanism and equipment setup of blood detection by dye 34, and (B) the retrieval of latent blood fingerprint on a glass slide based on dye 34 in mock crime scene 
A)

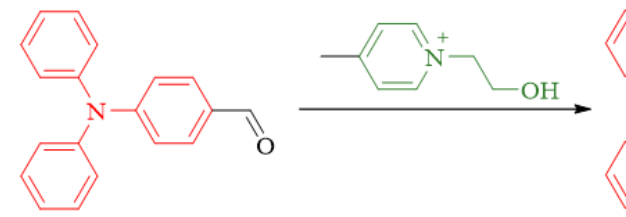

B)

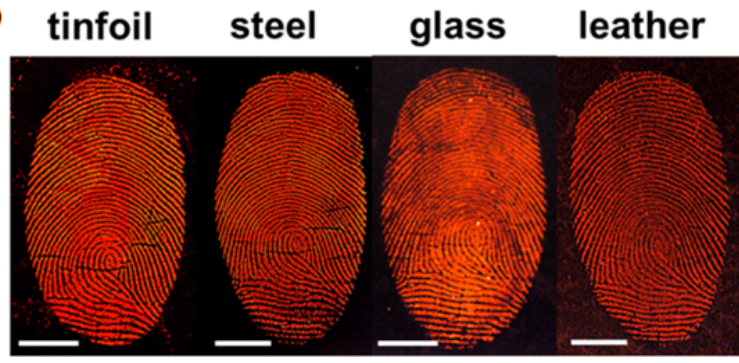

36

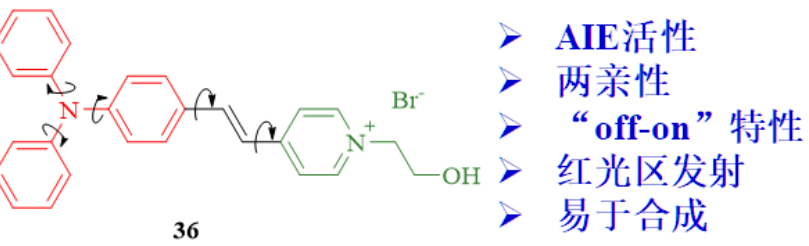

C)
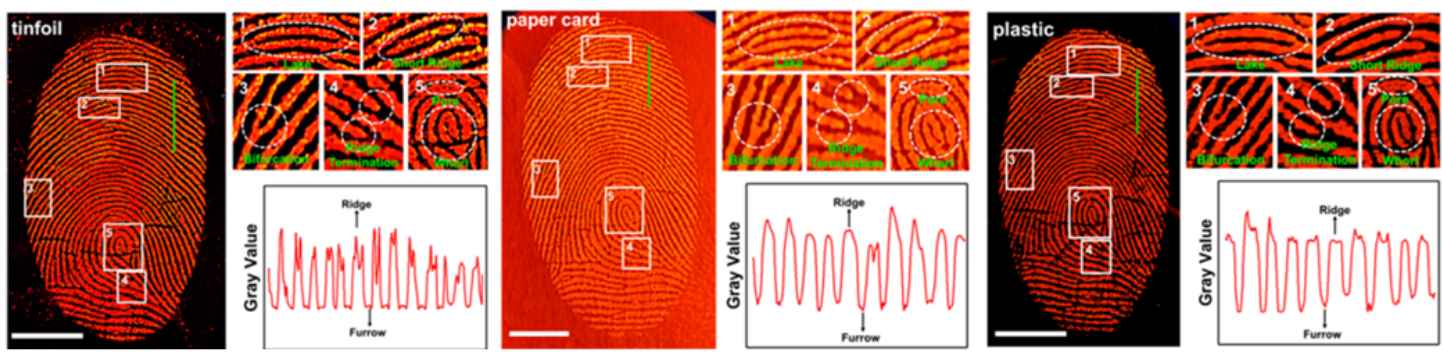

图 5 (A)染料 $\mathbf{3 6}$ 的合成路线及其特性、(B)染料 $\mathbf{3 6}$ 的纯水溶液显现不同客体上潜指纹的荧光成像图和(C)相关客体上指纹的一级、 二级和三级细节结构信息(绿线处指纹纹线和小犁沟之间的苂光强度变化) ${ }^{[65]}$

Figure 5 (A) Schematic of the synthesis of dye 36, (B) the whole LFPs on different substrates developed by a dye $\mathbf{3 6}$ pure aqueous solution, and (C) level 1, level 2, and level 3 details of local LFPs on foil, paper card, and plastic developed by a dye $\mathbf{3 6}$ aqueous solution (the variations of the fluorescence intensity between the fingerprint ridges and furrows across the green line)

A)

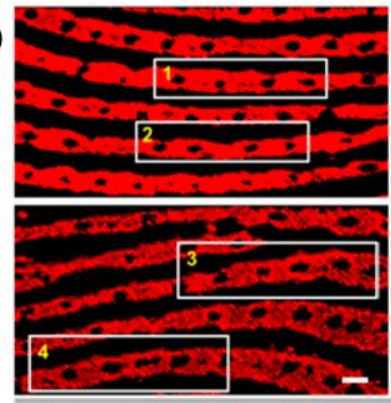

B)

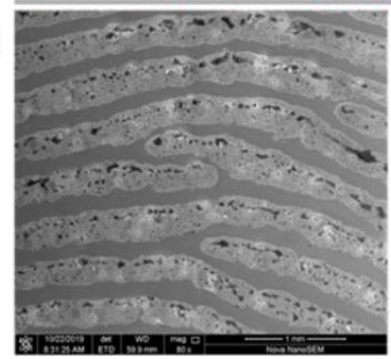

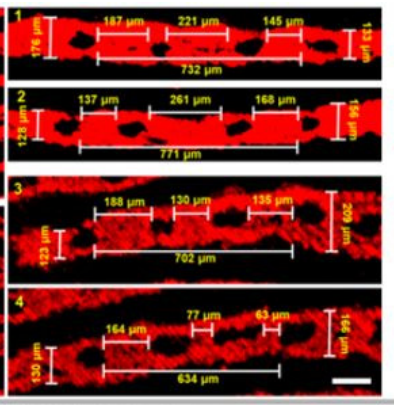

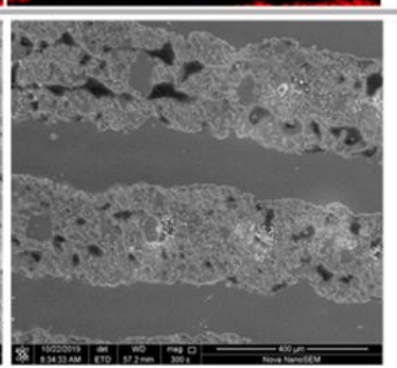

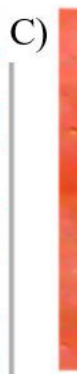
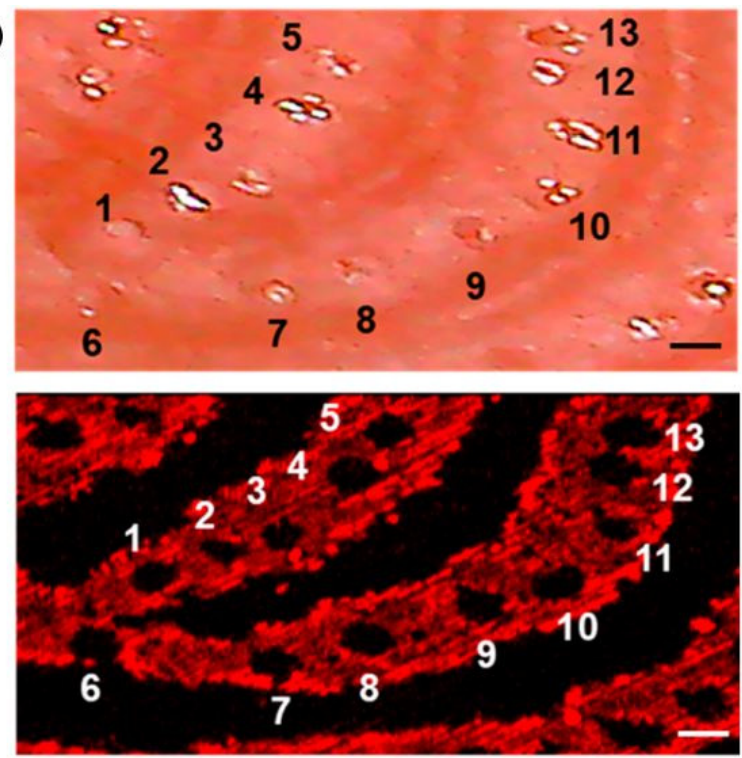

图 6 (A)对潜指纹部分区域的荧光显微图像及 3 级显微细节分析和汗腺孔(直径 80 120 nm) 每隔 100 200 nm 沿脊线周期性地 排列、(B)指纹的 SEM 图像、(C)手指上的真指纹(上)和在基底上苂光显现后的指纹(下)分叉处的汗孔数量和位置分布 ${ }^{[65]}$

Figure 6 (A) Fluorescence microscopic images for partial region of the latent fingerprints and the analysis of level 3 microscopic details and the sweat pores (diameter $80 \sim 120 \mathrm{~nm}$ ) are identified to be aligned periodically every $100 \sim 200 \mathrm{~nm}$ along the ridges, (B) SEM images of the fingerprint, and (C) number and location distribution of sweat pores on the bifurcation of the real fingerprint (top) on the finger and its developed fingerprint (bottom) on a substrate

针 37 的 $\mathrm{CH}_{3} \mathrm{CN} / \mathrm{H}_{2} \mathrm{O}$ 体系从明亮的蓝色荧光至蓝绿苂光 发光, 具有 $\mathrm{AEE}$ 性质. 探针 37 的 $\mathrm{CH}_{3} \mathrm{CN} / \mathrm{H}_{2} \mathrm{O}$ 溶液体系
协同 “502” 胶熏显技术实现了对多种客体上潜指纹的 苂光显现，指纹的一级、二级乃至三级结构都可观察到. 
此外, 将 AIE 分子 37 作为苂光母核, 外围包裹磷脂酰胆 碱、聚氧丙烯聚氧乙烯共聚物(F127)和两亲性聚乙二醇 自组装形成的壳, 形成 “壳一核” 苂光纳米颗粒. 由于 “壳” 的亲水性，因此当协同 “502” 胶熏显潜指纹时，潜 指纹的显现效果较差, 这也从侧面证实了该潜指纹显现 技术的机理是由 37 所形成的纳米颗粒与 “ 502 ” 胶在潜 指纹纹线上形成的白色多孔聚合物有着强烈的疏水一疏 水吸附作用, 从而实现对潜指纹的显现. 这种潜指纹显 现技术是一种简单、易于操作的方法, 有望被一线办案 人员用于现场潜指纹的提取.

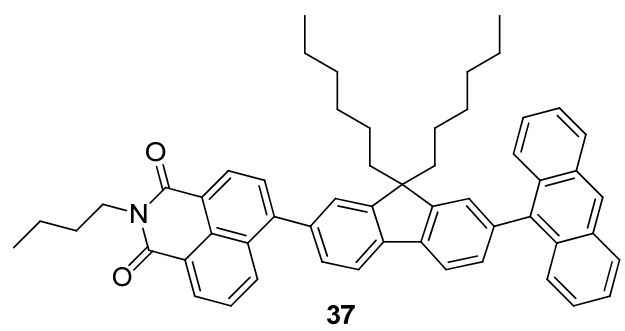

最近, 本课题组 ${ }^{[59]}$ 报道了一例以四苯乙烯为苂光 母体的苂光探针 38, 分别用直接浸泡法和协同 “502” 胶熏显技术两种方法显现多种客体上的潜指纹(图 7), 并通过苂光光谱、灰度值和 SEM 三种方法考察了两种 潜指纹显现方法对潜指纹显现性能的响应行为. 潜指纹 显现结果表明，通过协同 “502”胶熏显技术可有效提高 潜指纹的成像质量, 并且可以观察到指纹的三级结构. 同时，探针 38 也成功实现了对不同客体上陈旧指纹(7、 16 和 $30 \mathrm{~d}$ ) 的显现. 此外, 通过 AFIS 进行的指纹匹配测 试表明，两种方法都得到了较为积极的匹配效果.

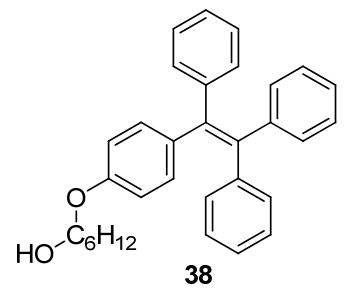

\section{3 聚合物有机材料在潜指纹显现中的应用研究}

共轭聚合物是一类含有饱和键与非饱和键的发光 单元共轭而形成的具有良好的光电子特质的聚合物材

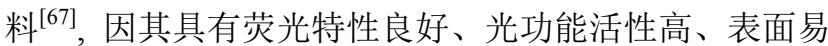
修饰、自组装能力及生物相容性好等优点, 被广泛用于 苂光成像 ${ }^{[68-69]}$ 、光动力诊疗 ${ }^{[70]}$ 、化学传感 ${ }^{[71-73]}$ 及法庭科 学 ${ }^{[74-76]}$ 等领域. 在这里, 本文后续将着重对半导体聚合 物点(Semiconducting polymer dots, Pdots)、共轭聚电解 质材料(Conjugated polyelectrolytes, CPEs)及低聚物-无 机杂化材料在潜指纹显现中的应用研究进行评述.

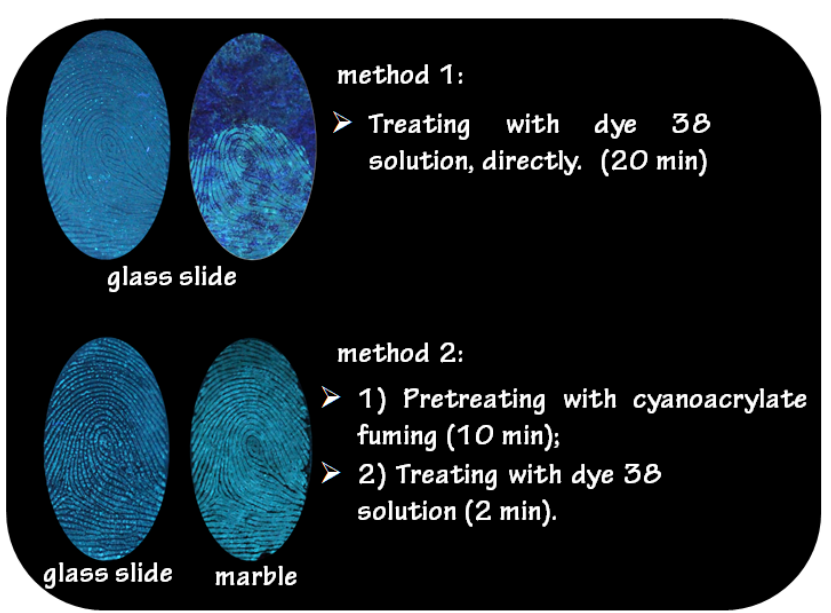

图 7 染料 38 的乙腈 -水溶液 $(V: V=1: 9, c=0.25 \mathrm{mmol} / \mathrm{L})$ 直接显现潜指纹荧光成像图像和协同 “ 502 ” 胶熏显法显现指 纹成像图像 ${ }^{[59]}$

Figure 7 Fluorescence images of the LFPs developed by dye $\mathbf{3 8}$ in $\mathrm{MeCN}$-water solution $(V: V=1: 9, c=0.25 \mathrm{mmol} / \mathrm{L})$, directly and the fluorescence images of the LFPs pretreated with the cyanoacrylate fuming method and incubating with the dye $\mathbf{3 8}$ solution

\subsection{Pdots 在潜指纹显现中的应用}

随着对聚合物研究的进一步深入，科研人员通过自 组装法、纳米沉淀法以及微乳液法将共轭聚合物制备成 了共轭聚合物纳米材料(conjugated polymer nanoparticles, CPNs). 在此基础上，按照纳米颗粒直径的大小、半 导体聚合物在其中所占的含量(或比重)及其内核的亲疏 水性, Chiu 等 ${ }^{[77]}$ 提出了 Pdots 的概念. 作为支撑纳米光 革命的四大纳米材料体系之一的 Pdots ${ }^{[78]}$, 不仅继承了 传统 CPNs 的优点, 而且还展现了其独特的优势, 如更 小的颗粒直径及紧凑的发光中心等，这类材料在潜指纹 的显现中也有着重要的应用.

2015 年, 吴长锋等 ${ }^{[25]}$ 合成了三种氧杂环丁烷功能 化的光交联半导体聚合物 39 41, 它们都在紫外区有 较强的吸收, 分别在蓝光、绿光和红光区域发射. 通过 纳米再沉淀法成功制备出了具有较高荧光强度、大 Stokes 位移及较好表面性质的光交联半导体聚合物点 (ox-Pdots). 将 ox-Pdots 溶液用于玻璃、金属及塑料等 多种客体上潜指纹的显现时，数分钟内就可得到高 质量的潜指纹显现成像图像。同时，他们也对 ox-Pdots 显现潜指纹技术的机理进行了解释，即在短时 紫外线照射下, ox-Pdots 与指纹纹线上残留物中的氨基 酸等物质之间发生交联反应，形成了三维空间网络结 构, 将指纹原位固定于客体表面, 呈现出了极大的稳定 性, 可以较好地抵抗外在干扰(图 8). 


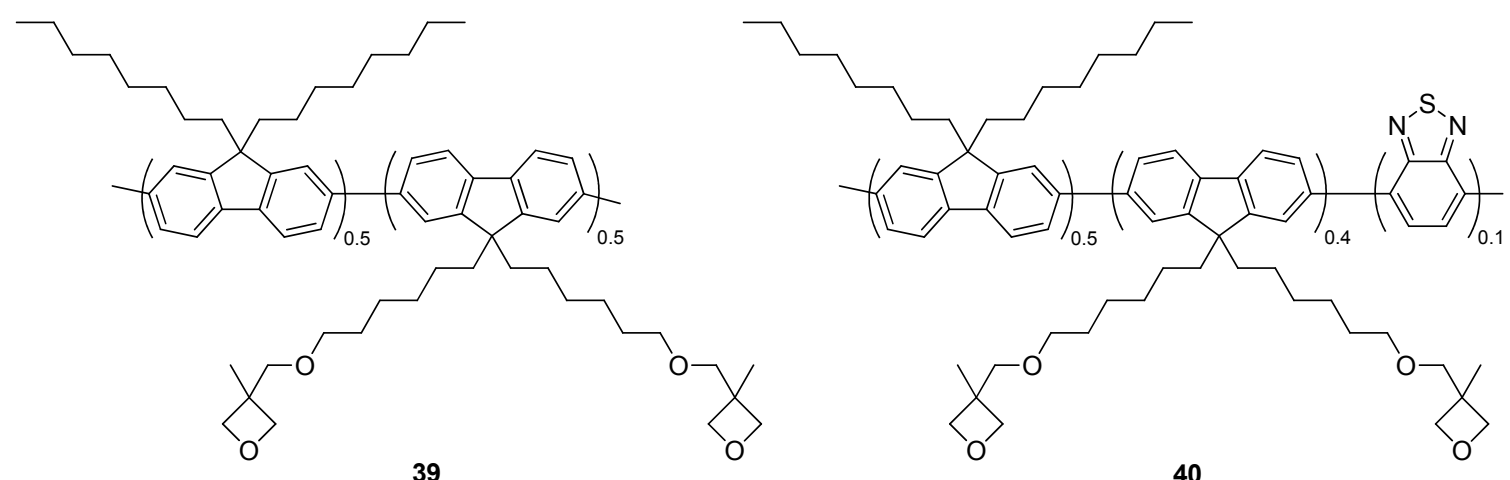

39

40
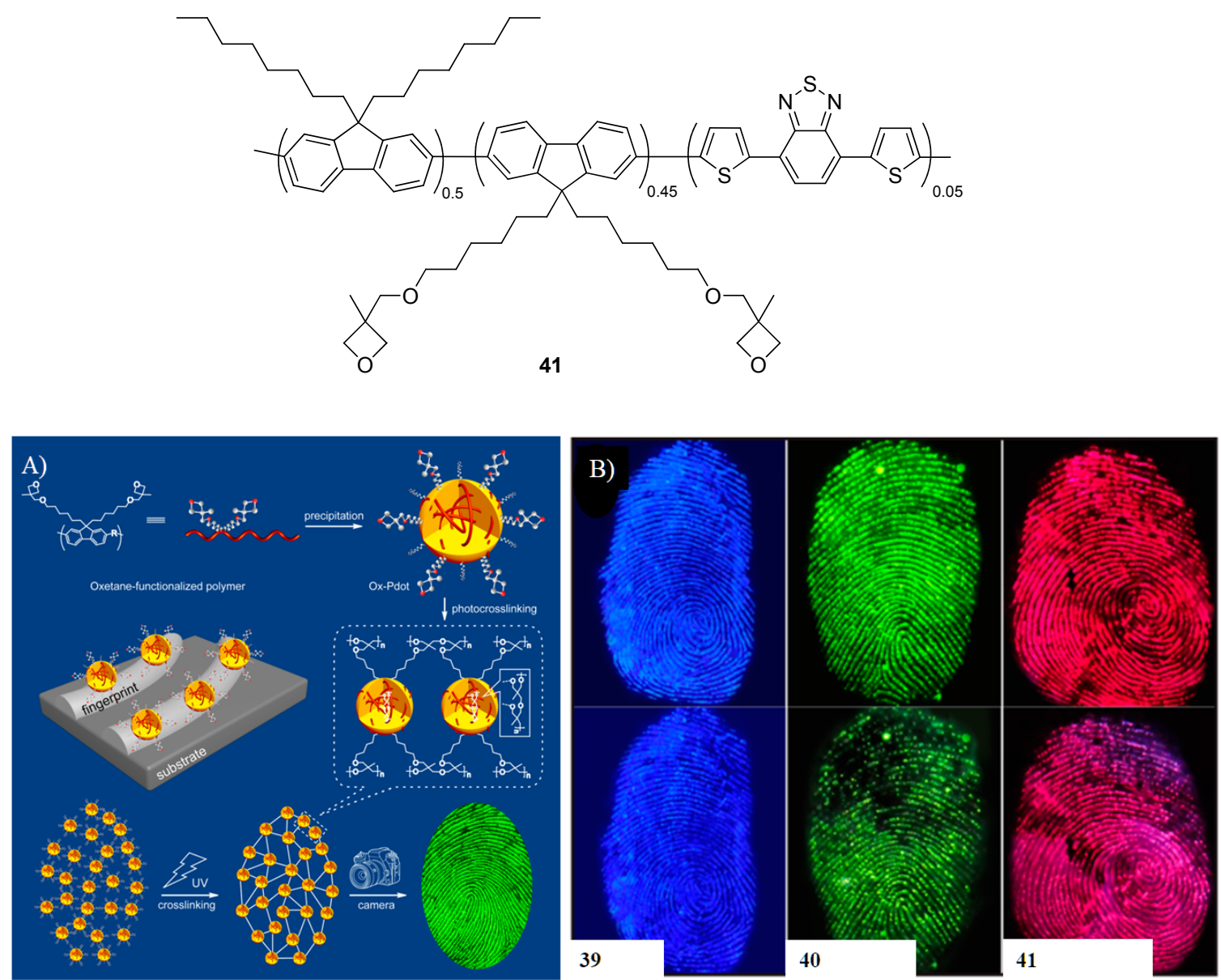

图 8 (A)光交联 ox-Pdots 用于潜指纹显现的示意图和(B)光交联 ox-Pdots 显现的潜指纹苂光图像(下排为四氢呋喃处理后的潜指纹 苂光图像 $)^{[25]}$

Figure 8 (A) Schematic illustration for visualization and covalent patterning of latent fingerprints with photo-cross-linkable ox-Pdots and (B) photo-cross-linkable Ox-Pdots (the bottom panel shows the respective images after tetrahydrofuran treatment)

Chan 等 ${ }^{[79]}$ 设计合成了两例处于近红外发射的 Pdots 42 和 43. 光谱实验表明, Pdot 42 在 $655 \mathrm{~nm}$ 处有发射峰, 苂光量子效率为 $0.29 ; \operatorname{Pdot} 43$ 在 $680 \mathrm{~nm}$ 处有发射峰, 苂 光量子效率为 0.32 . 此外, 共聚焦荧光光谱实验表明, Pdot 42 显现潜指纹时, 有指纹处相较于无指纹处的苂 光发射波长蓝移了约 $14 \mathrm{~nm}$, 苂光强度增强了约 1.1 倍, 而 Pdot 43 显现潜指纹时, 有指纹处相较于无指纹处的 荧光发射波长蓝移了约 $50 \mathrm{~nm}$, 苂光强度增强了约 1.8
倍. 综上考虑, 在后续的研究中, 他们对 Pdot 43 显现潜 指纹的性能做了详细研究. 该研究的亮点在于将茛三酮 嵌入至 Pdot 43 的空腔内, 实现了对多孔或非多孔客体 上潜指纹的比色与苂光双模式显现(图 9). 研究结果表 明，通过这种技术可实现对潜指纹的直接肉眼可视化， 或在 360 500 nm 的光源激发下, 实现对潜指纹的苂光 显现，且能够高对比度、高选择性、低背景干扰地观察 到指纹的一级、二级和三级结构(图 10). 这种基于 Pdots 

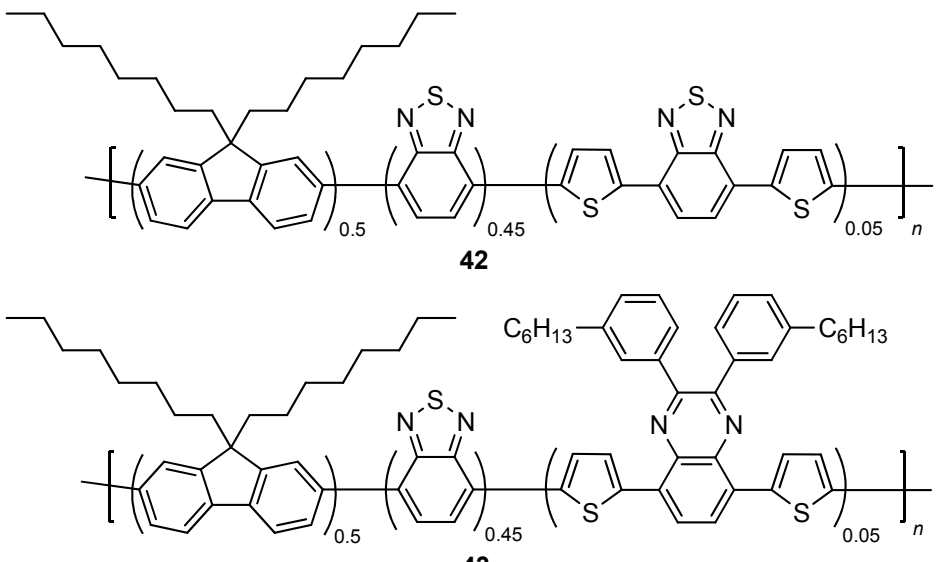

43

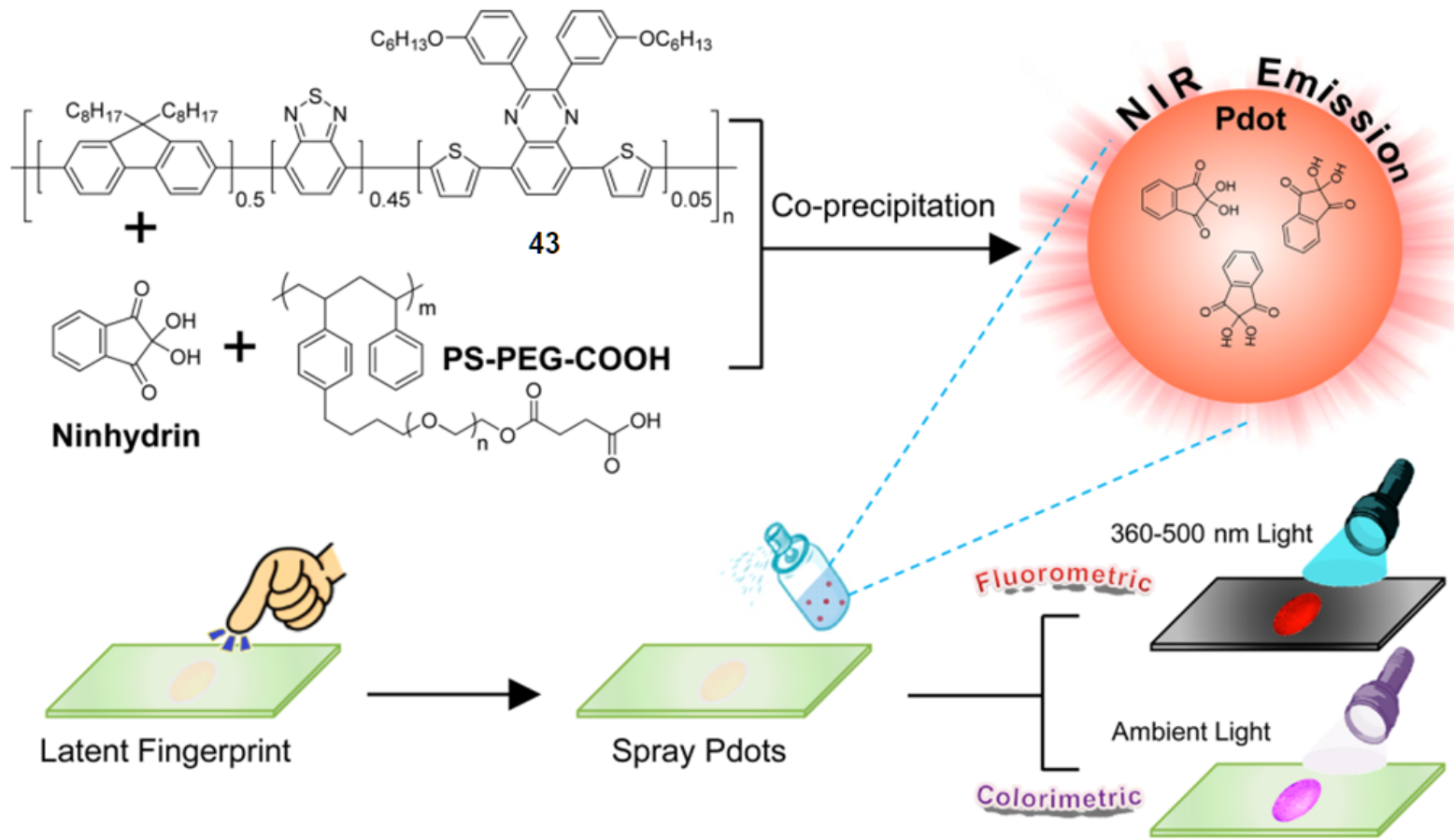

图 9 基于 Pdots 的双模式显现潜指纹的原理图 ${ }^{[79]}$

Figure 9 Schematic showing the detection of latent fingerprints with dual-readout assay based on Pdots

Note: First, Pdot 43, carboxyl-functionalized polystyrene PS-PEG-COOH, and ninhydrin dyes were mixed well in THF and then coprecipitated in water under vigorous sonication to form ninhydrin-embedded Pdot 43. The Pdot solution was then sprayed onto latent fingerprint regions to image fingerprints with dual (colorimetric and fluorometric) readouts
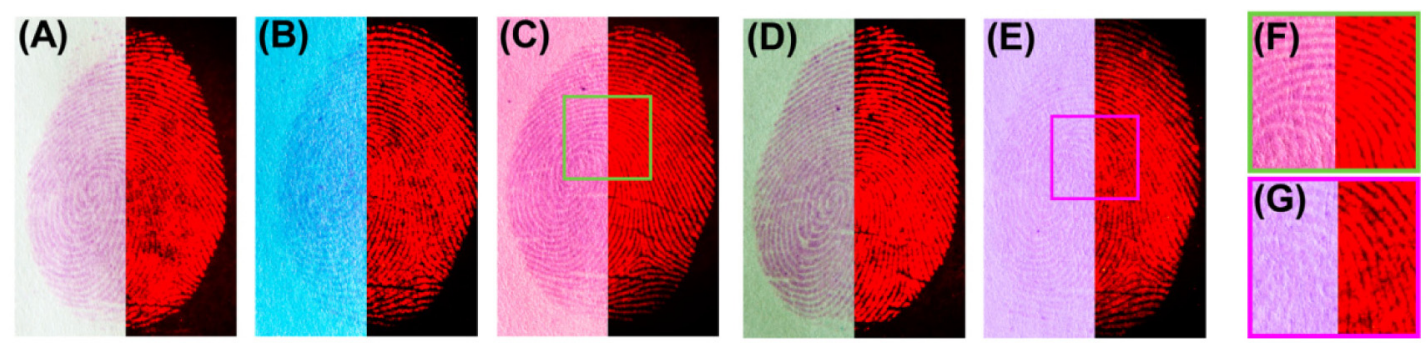

图 10 Pdot 43 水溶液显现不同颜色纸张客体上的潜指纹成像图 ${ }^{[79]}$

Figure 10 Images of LFPs developed with Pdot $\mathbf{4 3}$ on papers with different colors

Left: under daylight; Right: under $450 \mathrm{~nm}$ light irradiation with an orange filter 
的双模式显现潜指纹技术为潜指纹的显现研究提供了 一种全新的思路.

\subsection{CPEs 在潜指纹显现中的应用}

近年来, 作为共轭聚合物另一个重要的分支一一共 轭聚电解质材料(Conjugated polyelectrolytes, CPEs)在潜 指纹显现应用中也有诸多报道. CPEs 是含有疏水性 $\pi$ 共 轭骨架和亲水性离子链的一类共轭聚合物材料. 疏水性 $\pi$ 共轭骨架具有独特的光化学性质, 亲水性离子链不仅 起到增强聚合物水溶性的作用, 而且还起到与多种带相 反电荷的物质(如蛋白质、氨基酸和表面活性剂等)发生 静电吸引的作用.

2015 年, Kwak 等 ${ }^{[80]}$ 将 CPEs 44 47 纳米颗粒悬浮 液协同具有合适亲水-亲油平衡值(hydrophile-lipophile balance, HLB)的表面活性剂, 实现了对潜指纹的喷酒显 现. 在表面活性剂的作用下, CPEs 中亲水的苂光团部分 从水溶液中转移至指纹纹线处, 并与之相互作用而聚集 沉积, 实现对潜指纹的荧光显现(图 11). 在该研究中, 他们研究了不同 HLB 值的表面活性剂对潜指纹显现效 果的影响, 并认为使用 HLB 值在 $10 \sim 15$ 间的 Tween 系 列的非离子型表面活性剂, 可以很好地协同 CPEs 纳米 颗粒显现潜指纹. 此外, 他们还将该方法延伸至传统的 有机水分散性染料, 如硫酸奎宁、罗丹明 $6 \mathrm{G}$ 及花青素 等，在表面活性剂的协同作用下都可以较好地显现潜指 纹.

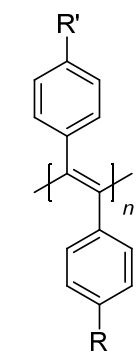

$\mathrm{R}, \mathrm{R}^{\prime}=\mathrm{SO}_{3} \mathrm{H}$ or $\mathrm{H}$

44

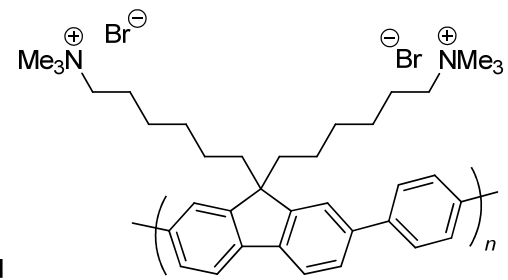

45

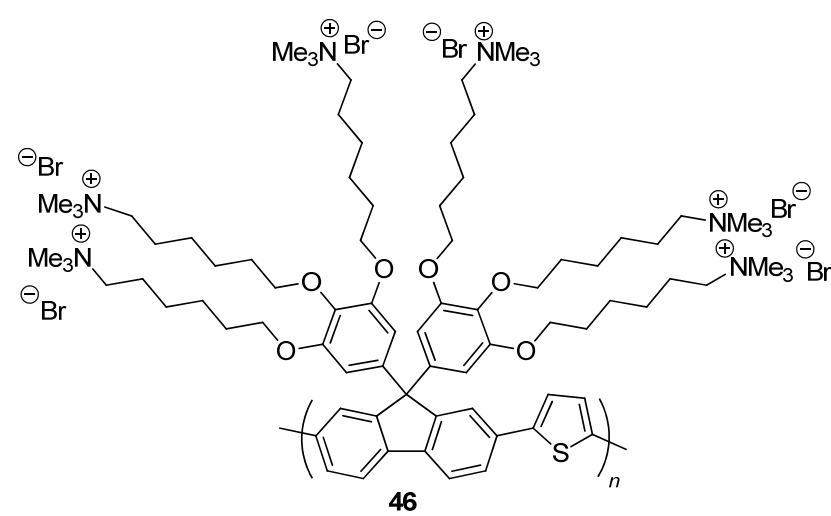

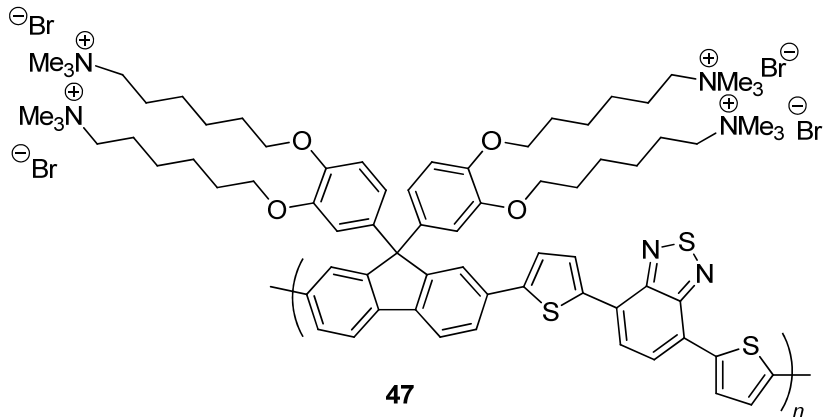

A)
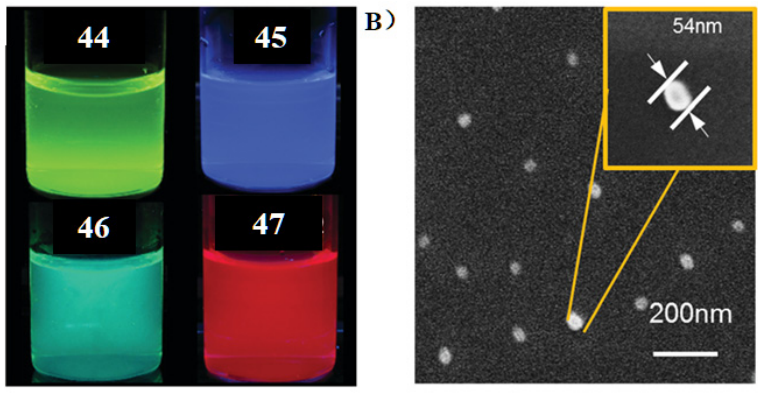

C)
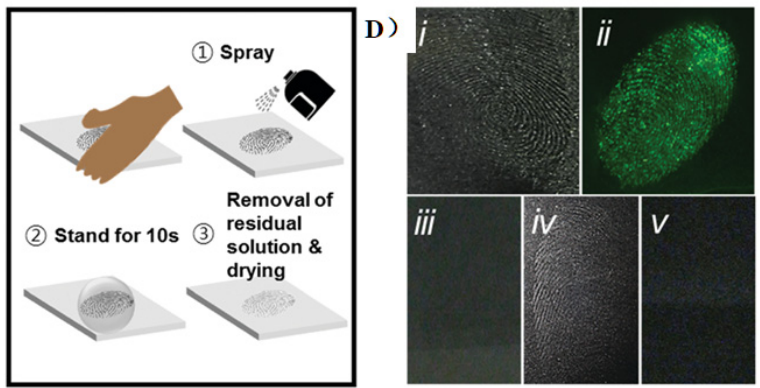

图 11 (A)水溶性 CPEs 胶体溶液的颜色 $\left(1 \times 10^{-5} \mathrm{~mol} / \mathrm{L}\right.$, 在波 长>365 nm 的紫外灯下激发)、(B)在干燥状态下染料 44 纳米 颗粒的 SEM 图像、(C)显现潜指纹的操作流程及(D)在玻璃客 体上使用质量分数为 $0.5 \%$ 的 44 的胶体溶液显现潜指纹的成 像图像 ${ }^{[80]}$

Figure 11 (A) Features of aqueous CPEs colloidal solutions $\left(1 \times 10^{-5} \mathrm{~mol} / \mathrm{L}\right.$, excited at $\lambda>365 \mathrm{~nm}$ under a UV lamp), (B) SEM image of $\mathbf{4 4}$ nanoparticles in the dry state, (C) scheme of the LFP-detection process and (D) features of LFPs on glass slides when stained using aq. 44 colloidal solutions $(w=0.5 \%)$ (i) No surfactant, (ii) $w$ (Tween 85$)=0.25 \%$, (iii) $w$ (SDS) $=0.25 \%$, (iv) $w($ Tween 80$)=0.25 \%$, and (v) $w(\operatorname{Span} 80)=0.25 \%$

随后，该课题组 ${ }^{[81}$ 将磺酸化聚二苯乙炔聚电解质 (44)溶液直接用于多种客体上的潜指纹高分辨率苂光显 现. 该方法显现潜指纹的机理是: CPE 44 在溶液中由于 受到分子内苯环的 $\pi-\pi$ 堆积的影响, 分子链的振动受到 抑制; 当 CPE 44 溶液与潜指纹接触后, CPE 44 分子链 间因负电荷相互排斥所形成的稳定构象被潜指纹残留 物中的带相反电荷的物质破坏后, 使得 CPE 44 分子内 苯环的 $\pi-\pi$ 堆积受到驰豫, 分子链间的距离得到增大, 苂光得到了极大的增强(图 12). 这种新的方法无需任何 其它后续处理, 就可以实现对多孔(如纸张)和非多孔(如 
A)

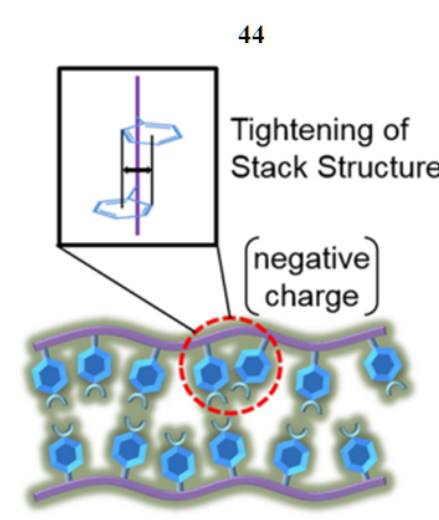

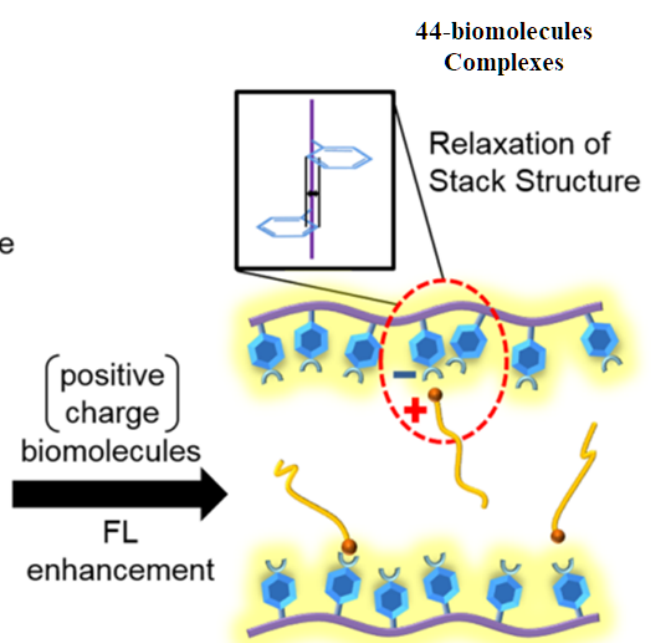

图 12 (A) CPE 44 与带电物质相互作用的示意图和(B) CPE 44 ( $w=0.50 \%$ 的丙醇溶液)对多种客体上汗潜指纹的显现(纸张、纸杯、 玻璃和塑料 $)^{[81]}$

Figure 12 (A) Schematic diagram of the interaction between CPE 44 and charged species and (B) features of sweat LFPs on various surfaces (paper, paper cups, glass, and plastic) stained using CPE 44 ( $w=0.50 \%$ in propanol)

玻璃、塑料)客体上汗潜指纹的高效显现. 因此，有理由 相信, 基于这种理念, 其它 CPEs 或带电荷的苂光团也 可以实现对多种客体上汗潜指纹的高分辨显现.

此外, Iyer 等 ${ }^{[76]}$ 报道了一例具有 AIE 效应、高荧光 强度和大 Stokes 位移 $(\approx 100 \mathrm{~nm})$ 的 CPE 48. 由于指纹残 留物中的脂多糖的脂肪组分 (如蜡酯、脂肪酸、角鲨烯 和胆固醇)与 48 的共轭主链(含有 AIE 荧光团)之间存在 着疏水-疏水相互作用, 且汗液成分(如氨基酸、蛋白质 及葡萄糖等)和 48 末端带正电荷部分发生静电吸引作 用, CPE 48 在溶液中所形成的纳米颗粒在指纹的纹线处 吸附聚集. 因此, 在这两种作用的协同下, CPE 48 在无 需任何后续处理(如熏显、表面活性剂), 且即使在有血 渍污染的条件下，都可以实现对多种客体上潜指纹的高 灵敏度、高对比度的显现, 且指纹的一到三级结构都可 以清晰地被观察到(图 13). 这种显现潜指纹的方法可用 于现场中潜指纹的检测, 并有提取其它法医物证和生物 识别应用的潜力.

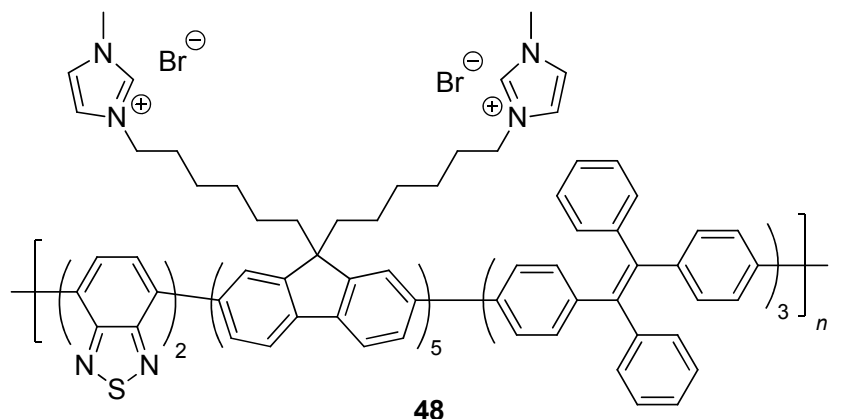

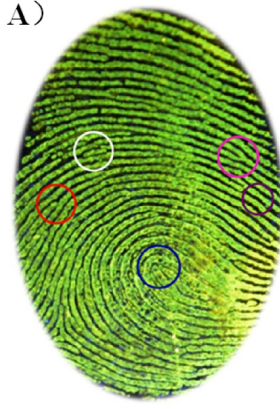

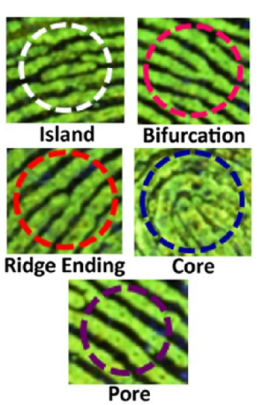

B) Undeveloped Blood laden LFP Blood laden LFP
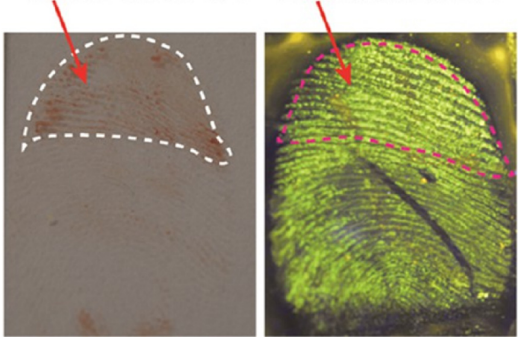

图 13 (A)在 $365 \mathrm{~nm}$ 光源的激发下, 用 CPE $48[0.2 \mathrm{mmol} / \mathrm{L}$, 甲醇/水溶液 $(V / V=2 / 8 \sim 3 / 7)]$ 显现后的高分辨率潜指纹荧光成 像照片及其 1 3 级细节结构和(B) CPE 48 对玻璃客体上含有 血渍的潜指纹的显现 ${ }^{[76]}$

Figure 13 (A) High-resolution photographs of latent fingerprints after developing with CPE $48\left[0.2 \mathrm{mmol} / \mathrm{L}\right.$, methanol $/ \mathrm{H}_{2} \mathrm{O}$ $(V / V=2 / 8 \sim 3 / 7)]$ solution under the excitation of UV illumination (365 nm) and (B) blood-laden LFP developed on a glass slide

\section{3 低聚物-无机杂化材料在潜指纹显现中的应用研 究}

共轭聚合物或低聚物从溶液状态变为纳米颗粒或 固体薄膜状态时, 往往遭受着 ACQ 效应的影响, 这极 
大地影响了该类材料的进一步开发应用. 目前, 主要有 两种策略用于解决 ACQ 效应: 一是改变分子的结构, 使其具有 AIE 效应; 二是将荧光团分散在矩阵内, 且这 种方法特别适用于共轭聚合物.

2017 年, Li 和 Cui 课题组 ${ }^{[82}$ 报道了一例硅烷修饰的 共轭低聚物(49), 并通过反相胶束法将其分散在硅矩阵 内, 得到了超强蓝色苂光的纳米颗粒(图 14), 量子效率 高达 $97 \%$. 所得到的苂光纳米颗粒具有稳定的光学性 质, 即使在紫外光的连续照射下, 都没有观察到光降解. 这种高量子效率和稳定性主要是因为低聚物被固定在 刚性的硅矩阵内, 限制了分子的旋转和振动, 并且避免 了外部环境的干扰. 此外, 作为概念验证, 他们将该荧 光硅纳米粉末用于多种客体上潜指纹的刷显时, 得到了 荧光增强的指纹，且在小犁沟和纹线之间具有较高的对 比度和分辨率. 与此类似，该课题组 ${ }^{[83]}$ 又报道了一例红 光发射的低聚物/二氧化硅杂化纳米材料(50), 并成功将 其用于有背景荧光客体(如塑料、纸张等)上潜指纹的刷 显.

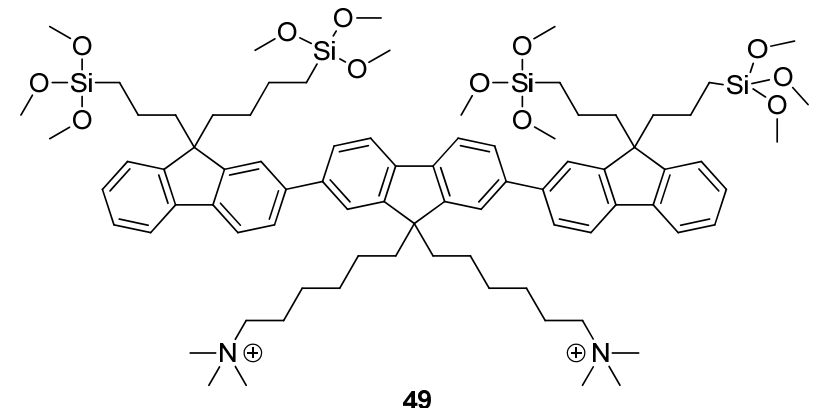

4 其它小分子有机材料在潜指纹显现中的应用 研究

于聪课题组 ${ }^{[84]}$ 提出了利用激基缔合物发光显现潜 指纹的设想，构建了三例基于二荎嵌苯的荧光探针 $(51 \sim 53)$, 并对该设想进行了实验论证及讨论. 探针 51 含有 4 个带正电荷的季铵盐，具有良好的水溶性，其在 固体状态下有较强的橙色荧光发光特性. 探针 51 在低 浓度时自聚集程度较低, 主要以单体形式存在, 但随着

A)

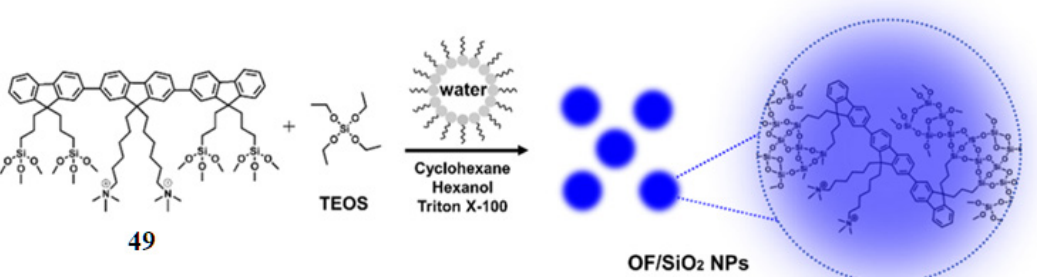

B)

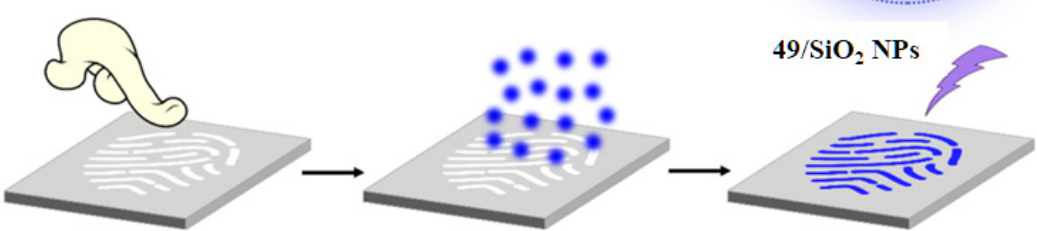

C)

49/ $\mathrm{SiO}_{2} \mathrm{NPs}$

Light

D)

$49 / \mathrm{SiO}_{2} \mathrm{NPs}$

UV

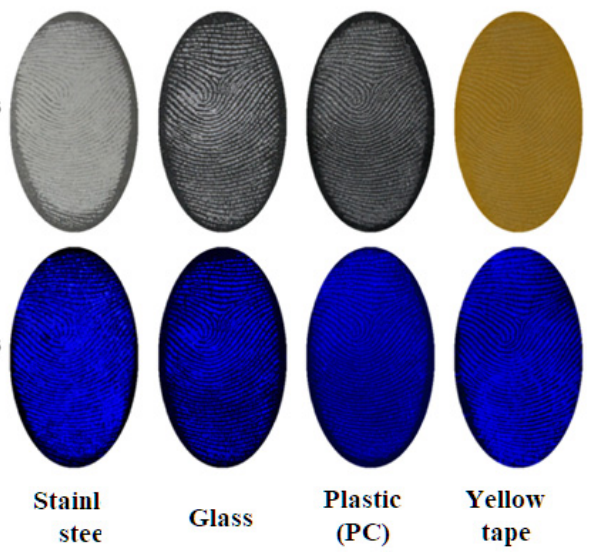

图 14 (A)用反相胶束法合成 $49 / \mathrm{SiO}_{2}$ 纳米颗粒的方法和在合成过程中所用到的物质的化学结构示意图、(B) $49 / \mathrm{SiO}_{2}$ 纳米颗粒荧 光显现潜指纹的步骤、(C)自然光条件下和(D)紫外光源激发 $(365 \mathrm{~nm})$ 时 $49 / \mathrm{SiO}_{2}$ 纳米颗粒刷显不同客体上的潜指纹成像图像 ${ }^{[82]}$

Figure 14 (A) Synthesis $49 / \mathrm{SiO}_{2} \mathrm{NPs}$ via reverse micelle method and chemical structures used in the process, (B) procedures for fingerprint development with $\mathbf{4 9} / \mathrm{SiO}_{2} \mathrm{NPs}$, and the images of LFPs from different substrates developed with $49 / \mathrm{SiO}_{2} \mathrm{NPs}$ under (C) daylight and (D) UV light (365 nm) 


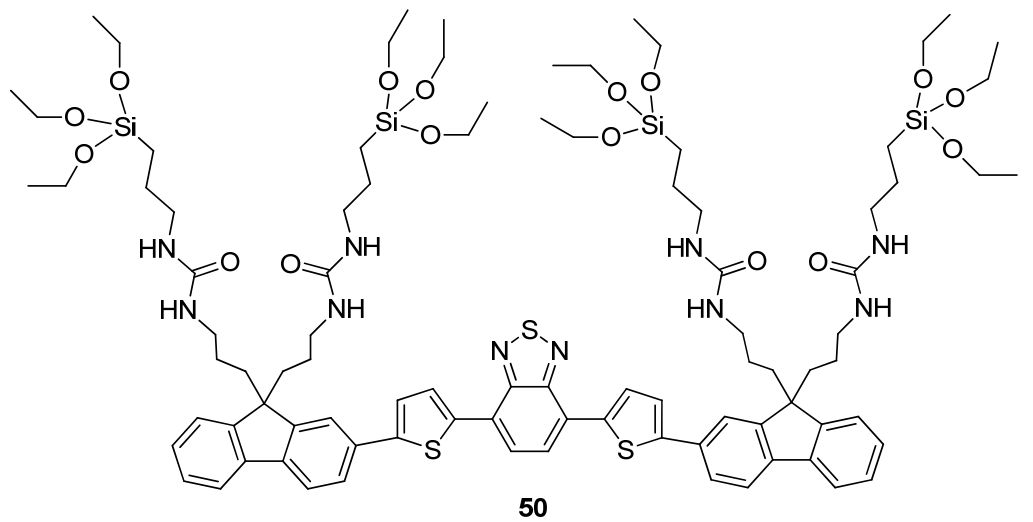

探针 51 的浓度增大，引起了单体和激基缔合物的荧光 转换. 潜指纹显现研究结果表明, 探针 51 溶液能够较好 地实现对潜指纹的显现，且指纹的二级结构清晰可见， 显现时间只要 $5 \mathrm{~min}$. 与之形成鲜明对比的是, 探针 $\mathbf{5 2}$ 和 53 分子内含有较少的正电荷或呈现电负性, 并不能 观察到潜指纹的成像图像. 这可能归各为: 带有正电荷 的探针 51 与潜指纹残留物中带负电荷的脂肪酸或其它 有机化合物发生了静电吸引作用, 探针 $\mathbf{5 1}$ 在溶液中形 成了分子内激基缔合物, 并形成强且宽的激基缔合物发 射峰; 而探针 52 和 53 分子内含有的正电荷较少或呈现 电负性, 其与潜指纹残留物的静电吸引作用变弱, 抑制 了激基缔合物聚集体的形成. 值得一提的是, 当用聚偏 二氟乙烯(PVDF)膜或硝化纤维素胶片对疑难客体(包括 纸张、木材和皮肤)上的潜指纹进行转移、显现时, 只需 $5 \mathrm{~s}$ 甚至更少的时间就可以得到高分辨率的指纹成像图 像, 指纹的细节结构, 甚至三级结构都可以被观察到. 这种潜指纹显现技术有望在现场中得到应用.

类似的，王克让和李小六课题组 ${ }^{[85]}$ 也基于激基缔 合物发光显现潜指纹的理念, 同样以二萗嵌苯为荧光母 核, 用三甘醇和乳糖对其结构修饰, 设计合成了一例新 颖的不对称萠酰亚胺衍生物 $\mathbf{5 4}$, 并将其用于潜指纹的 显现研究. 用 PVDF 膜转移潜指纹, 并将该 PVDF 膜在 54 的溶液中浸泡 $5 \mathrm{~h}$ 取出, 可直接在日光下观察到明显 的红色指纹成像图像. 此外, 在 $365 \mathrm{~nm}$ 紫外灯的照射 下, 尽管 PVDF 膜有红色荧光背景, 但也可观察到潜指

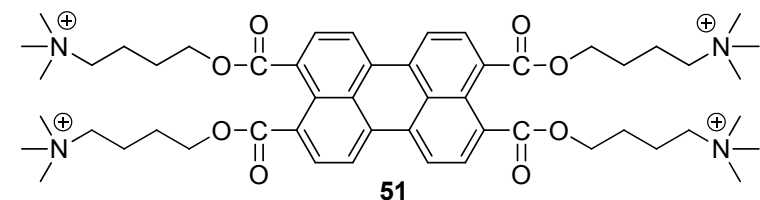<smiles>CC(C(=O)O)n1c(=O)c2ccc3c4ccc(c1=O)c(c1ccc5c(=O)n(C(C)C(=O)O)n(C(C)C(=O)O)c(=O)c6ccc4c5c61)c23</smiles>

52<smiles>C[N+](C)(C)CCCN1C(=O)c2ccc3c4ccc5c6c(ccc(c7ccc(c2c37)C1=O)c64)C(=O)N(CCC[N+](C)(C)C)C5=O</smiles>

纹的红色荧光成像图像. 这也说明, 54 在溶液中所形成 的聚集体倾向于与指纹纹线中的油性残留物发生疏水疏水相互作用而进行吸附聚集. 相较于探针 51, 54 显现 潜指纹的优点在于其在日光下, 就可观察到清晰的潜指 纹成像图像, 但也不能忽视它的缺点, 54 显现潜指纹的 时间较长 $(5 \mathrm{~h})$, 且没有探索其对疑难客体上潜指纹的显 现能力.

最近，黄华南等 ${ }^{866}$ 首次通过后修饰策略构建了系 列 B、N 改性的苯并葱共轭聚合物. 在苯并葱的主骨架 上通过亲电澳化和钯催化的交叉偶联反应，引入不同的 取代基，系统地调控这些苯并葱衍生物的光电性质. 由<smiles></smiles> 
于亲脂性极性键组成的共轭体系可能会与各种带电物 质, 如蛋白质、氨基酸和表面活性剂, 发生强的静电吸 引作用. 因此, 他们以易于合成的共轭二聚体 $\mathbf{5 5}$ 为例, 探索 B、N 改性的苯并葱共轭聚合物在潜指纹显现中的 应用研究. 潜指纹显现研究实验表明, 共轭二聚体 $\mathbf{5 5}$ 可 以很好地实现对玻璃、铝板、塑料和铁器上潜指纹的喷 酒显现, 指纹的二级结构清晰可见, 这也为氮杂嗍化学 在潜指纹荧光成像技术中的应用开辟了可能性.

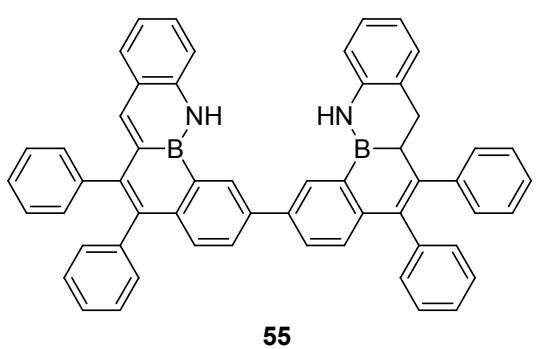

\section{5 结论与展望}

传统的指纹技术研究有三大方向一一显现、鉴定和 识别系统: 潜指纹显现是鉴定的基础, 鉴定是潜指纹显 现的目的，识别系统是潜指纹鉴定的信息化应用. 这也 表明潜指纹显现质量的好坏, 直接影响着相关案件的侦 破和法庭诉讼的成败. 因此, 开发出结构新颖的有机染 料用于潜指纹的显现具有重要的实战价值. 近年来, 随 着化学、生物及医学等学科的发展, 越来越多的科研工 作者致力于潜指纹显现新材料或新技术的开发研究工 作，但潜指纹显现在高效、灵敏、无损以及低毒等方面 仍然面临不小的挑战.

本文首先对目前在实战中较为广泛用于潜指纹显 现的传统有机材料作了简要回顾, 这些传统的有机材料 在一定程度上满足了实际工作的需求, 但它们各自存在 的缺陷并不能够被忽视, 这也是迫使研发人员致力于开
发新的潜指纹显现材料或新技术的动力所在. 为了克服 这些缺陷，科研工作者们开发了许多的新颖的有机苂光 材料，如聚集诱导发光材料、共轭聚合物材料及其它有 机荧光材料等，用于潜指纹的显现研究，这些新的潜指 纹显现有机苂光材料往往具有优良的光学性质、较好的 稳定性、低毒等特点. 本文较为详细地综述了近十年来 新出现的有机荧光材料在潜指纹显现中的应用研究进 展. 从所综述的文献不难得知, 这些新颖的有机苂光材 料显现潜指纹时, 在某种程度上展现出对潜指纹高对比 度、高选择性、高灵敏度及无损显现等优点. 本文中所 讨论的用于潜指纹显现的 AIE 分子和聚合物有机染料 总体情况如表 1 和表 2 所示, 这对于有机苂光材料显现 潜指纹技术的发展具有良好的指导意义. 但是随着对潜 指纹显现要求的进一步提高, 仍然有以下几个方面需要 考虑: (i)这些新的用于潜指纹显现的有机苂光材料或新 技术往往还只是停留在实验室中，离实际应用还存有一 定的距离; (ii)所报道的这些有机苂光材料, 往往对汗 (或油)潜指纹显现效果较好, 且只有为数不多的新材料 可以实现对血潜指纹的显现; (iii) 只有极少数新材料能 够实现对疑难客体(如渗透性客体、有较强背景荧光的 客体等)上的潜指纹的高效显现; (iv)针对潜指纹特定的 残留物(如爆炸物、毒品等), 构建新型的有机苂光新材 料, 或与其它分析方法联用, 对潜指纹残留物进行识别; (v)所开发的新材料或新技术需无碍后续生物检材的提 取; (vi)对其它方法提取指纹失败后的补救显现; (vii)根 据实战需要, 将那些对潜指纹显现效果较好的新材料推 广至公安基层一线使用. 相信随着这几方面工作的深入 开展，这些新的用于潜指纹显现的有机苂光材料或新技 术不仅可以促进潜指纹显现技术的进一步发展，而且还 可以为公安实战需求提供技术支撑，更好地为 “平安中 国” 保驾护航．同时，我们也相信本文可为这类新颖潜 指纹显现有机苂光材料的开发提供思路和参考.

表 1 所报道的在潜指纹显现应用中的 AIE 染料

Table 1 Reported AIE dyes for LFPs development.

\begin{tabular}{|c|c|c|c|c|c|c|}
\hline Dye & $\lambda_{\mathrm{ex}} / \lambda_{\mathrm{em}}{ }^{a} / \mathrm{nm}$ & Concentration & LFP origin & Time & Solvent $(V / V)$ & Ref. \\
\hline 18 & $365 / 450 \sim 480$ & $0.25 \mathrm{mmol} \cdot \mathrm{L}^{-1}$ & Sebaceous & Incubate $5 \mathrm{~min}$ & $\mathrm{CH}_{3} \mathrm{CN} / \mathrm{H}_{2} \mathrm{O}(6 / 4$ or $5 / 5)$ & [23] \\
\hline 19 & $365 / 460 \sim 480$ & $0.1366 \mathrm{~g} \cdot \mathrm{L}^{-1}$ & Sebaceous & Incubate $5 \mathrm{~min}$ & $\mathrm{CH}_{3} \mathrm{CN} / \mathrm{H}_{2} \mathrm{O}(5 / 5$ or $3 / 7)$ & \multirow{2}{*}{ [58] } \\
\hline 20 & $365 / 460 \sim 480$ & $0.1346 \mathrm{~g} \cdot \mathrm{L}^{-1}$ & Sebaceous & Incubate $5 \mathrm{~min}$ & $\mathrm{CH}_{3} \mathrm{CN} / \mathrm{H}_{2} \mathrm{O}(7 / 3$ or $6 / 4)$ & \\
\hline 21 & $365 / 650$ & $0.25 \mathrm{mmol} \cdot \mathrm{L}^{-1}$ & Sebaceous & Incubate $20 \mathrm{~min}$ & $\mathrm{CH}_{3} \mathrm{CN} / \mathrm{H}_{2} \mathrm{O}(3 / 7$ or $2 / 8)$ & [24] \\
\hline 22 & $365 / 475$ & $0.25 \mathrm{mmol} \cdot \mathrm{L}^{-1}$ & Sebaceous & Incubate $20 \mathrm{~min}$ & $\mathrm{CH}_{3} \mathrm{CN} / \mathrm{H}_{2} \mathrm{O}(4 / 6$ or $3 / 7)$ & [53] \\
\hline 23 & $365 / 526$ & $0.25 \mathrm{mmol} \cdot \mathrm{L}^{-1}$ & Sebaceous & Incubate 2 min (glass: $10 \mathrm{~min}$ ) & $\mathrm{CH}_{3} \mathrm{CN} / \mathrm{H}_{2} \mathrm{O}(1 / 1)$ & \multirow{2}{*}{ [60] } \\
\hline 24 & $365 / 518$ & $0.25 \mathrm{mmol} \cdot \mathrm{L}^{-1}$ & Sebaceous & Incubate 2 min (glass: $10 \mathrm{~min}$ ) & $\mathrm{CH}_{3} \mathrm{CN} / \mathrm{H}_{2} \mathrm{O}(6 / 4)$ & \\
\hline 26 & $365 / 564$ & $1 \mathrm{mmol} \cdot \mathrm{L}^{-1}$ & Sebaceous & Incubate $5 \mathrm{~min}$ & $\mathrm{CH}_{3} \mathrm{CN} / \mathrm{H}_{2} \mathrm{O}(1 / 9)$ & [61] \\
\hline 27 & $365 / 525$ & $0.1 \mathrm{mmol} \cdot \mathrm{L}^{-1}$ & Sebaceous & Incubate $5 \mathrm{~min}$ & $\mathrm{CH}_{3} \mathrm{CN} / \mathrm{H}_{2} \mathrm{O}(1 / 9)$ & [62] \\
\hline 28 & \multicolumn{2}{|c|}{$365 / \approx 510,549$} & & & & \\
\hline 29 & \multicolumn{2}{|c|}{$365 / \approx 520, \approx 5600.1 \mathrm{mmol} \cdot \mathrm{L}^{-1}$} & Sebaceous & Incubate $1 \mathrm{~min}$ & Ethanol/ $\mathrm{H}_{2} \mathrm{O}(1 / 9)$ & [63] \\
\hline 30 & \multicolumn{2}{|c|}{$365 / \approx 530, \approx 570$} & & & & \\
\hline
\end{tabular}




\begin{tabular}{|c|c|c|c|c|c|c|}
\hline Dye & $\lambda_{\mathrm{ex}} / \lambda_{\mathrm{em}}{ }^{a} / \mathrm{nm}$ & Concentration & LFP origin & Time & Solvent $(V / V)$ & Ref. \\
\hline $34^{b}$ & $365 / 470$ & $0.25 \mathrm{mmol} \cdot \mathrm{L}^{-1}$ & Blood & Incubate $5 \mathrm{~min}$ & $\mathrm{DMSO} / \mathrm{H}_{2} \mathrm{O}(1 / 9)$ & [8] \\
\hline 36 & $405 / 652$ & $30 \mu \mathrm{mol} \cdot \mathrm{L}^{-1}$ & Sebaceous & Incubate $30 \mathrm{~s}$ & Pure water & [65] \\
\hline 37 & $365 / \approx 525$ & $0.2 \mathrm{mg} \bullet \mathrm{mL}^{-1}$ & Sebaceous & Fuming $10 \mathrm{~min}+$ Incubate $7 \mathrm{~min}$ & Ethanol/ $\mathrm{H}_{2} \mathrm{O}(1 / 1)$ & [66] \\
\hline $\mathbf{3 8}^{c}$ & $365 / 480$ & $0.25 \mathrm{mmol} \cdot \mathrm{L}^{-1}$ & Sebaceous & $\begin{array}{l}\text { Incubate } 20 \mathrm{~min} \\
\text { Fuming } 10 \mathrm{~min}+\text { Incubate } 2 \mathrm{~min}\end{array}$ & $\mathrm{CH}_{3} \mathrm{CN} / \mathrm{H}_{2} \mathrm{O}(2 / 8)$ & [59] \\
\hline
\end{tabular}

${ }^{a}$ The excitation wavelength $\left(\lambda_{\mathrm{ex}}\right)$ is the wavelength of the source in visualizing the LFPs. ${ }^{b}$ The probe 34 is nonemissive in the aggregation state, and the conjugation is disrupted through an addition reaction with a thiol group forming an emissive product $\mathbf{3 5}$ that have the maximum emission wavelength at 470 nm. ${ }^{c}$ The LFPs can be directly visualized by incubating with the dye $\mathbf{3 8}$ solution and pretreating with the cyanoacrylate fuming combined with staining method, respectively.

表 2 所报道的在潜指纹显现应用中的聚合物有机材料

Table 2 Reported polymer organic materials for LFPs development

\begin{tabular}{|c|c|c|c|c|c|c|}
\hline Dye & $\lambda_{\mathrm{ex}} / \lambda_{\mathrm{em}}{ }^{a} / \mathrm{nm}$ & Concentration & LFP origin & Time & Solvent & References \\
\hline 39 & $365 / 430$ & \multirow{3}{*}{$500 \mu \mathrm{g} / \mathrm{mL}$} & \multirow{3}{*}{ Sebaceous } & & \multirow{3}{*}{ Pure water } & \multirow{3}{*}[25]{} \\
\hline 40 & $365 / 530$ & & & \multirow{2}{*}{ Irradiated with a UV Lamp for $10 \mathrm{~s}$} & & \\
\hline 41 & $365 / 650$ & & & & & \\
\hline & & & & & Nonporous substrate: water & \\
\hline 43 & $450 / 680$ & - & Sebaceous & Incubate $10 \mathrm{~min}$ & Porous substrates: & {$[79]$} \\
\hline & & & & & Acetone $/ \mathrm{H}_{2} \mathrm{O}(1 / 19 \sim 2 / 8)$ & \\
\hline $44^{b}$ & $>365 / \approx 530$ & $0.5 \%(w)$ & Sweat & Incubate a few seconds & Propanol & {$[81]$} \\
\hline $44^{b}$ & $>365 / 523$ & \multirow{4}{*}{$0.5 \%(w)$} & \multirow{4}{*}{ Sebaceous } & \multirow{4}{*}{ Incubate $10 \mathrm{~s}$} & \multirow{4}{*}{ Pure water $^{c}$} & \multirow{4}{*}[80]{} \\
\hline 45 & $>365 / 420$ & & & & & \\
\hline 46 & $>365 / 475$ & & & & & \\
\hline 47 & $>365 / 642$ & & & & & \\
\hline 48 & $365 / \approx 560$ & $0.2 \mathrm{mmol} / \mathrm{L}$ & Sebaceous \& Sweat & Incubate $\sim 1 \mathrm{~min}$ & Methanol/ $\mathrm{H}_{2} \mathrm{O}(2 / 8 \sim 3 / 7)$ & [76] \\
\hline
\end{tabular}

${ }^{a}$ The excitation wavelength $\left(\lambda_{\mathrm{ex}}\right)$ is the wavelength of the source in visualizing the LFPs. ${ }^{b}$ There two methods can be used to visualize the sweat LFPs and sebaceous LFPs, respectively, based on CPE 44. ${ }^{c}$ The non-ionic Tween-series surfactants with HLB values of 1015 were the most effective as phase-transfer agents of CPE $44 \sim 47$.

\section{References}

[1] Cadd, S.; Islam, M.; Manson, P.; Bleay, S. Sci. Justice 2015, 55, 219

[2] Wang, Y.; Wang, J.; Ma, Q.; Li, Z.; Yuan, Q. Nano Res. 2018, 11, 5499 .

[3] Leggett, R.; Lee-Smith, E. E.; Jickells, S. M.; Russell, D. A. Angew. Chem., Int. Ed. 2007, 46, 4100.

[4] de la Hunty, M.; Spindler, X.; Chadwick, S.; Lennard, C.; Roux, C. Forensic. Sci. Int. 2014, 244, e48.

[5] Wang, Z.; Jiang, X.; Liu, W.; Lu, G.; Huang, X. Sci. China: Chem. 2019, 62, 889 .

[6] Peng, D.; Wu, X.; Liu, X.; Huang, M.; Wang, D.; Liu, R. ACS Appl. Mater. Interfaces 2018, 10, 32859.

[7] Wang, J.; Wei, T.; Li, X.; Zhang, B.; Wang, J.; Huang, C.; Yuan, Q Angew. Chem., Int. Ed. 2014, 53, 1616.

[8] Wang, Z.; Zhang, P.; Liu, H.; Zhao, Z.; Xiong, L.; He, W.; Kwok, R. T. K.; Lam, J. W. Y.; Ye, R.; Tang, B. Z. ACS Appl. Mater. Interfaces 2019, 11, 17306.

[9] Wang, J.; Ma, Q.; Liu, H.; Wang, Y.; Shen, H.; Hu, X.; Ma, C.; Yuan, Q.; Tan, W. Anal. Chem. 2017, 89, 12764.

[10] Zheng, L.; Ma, R.; Li, Q.; Sang, Y.; Wang, H.; Wang, B.; Yan, Q.; Chen, D.; Wang, M.; Feng, W.; Zhao, Y. Anal. Bioanal. Chem. 2019, 411, 4151.

[11] Dalrymple, B.; Duff, J.; Menzel, E. J. Forensic Sci. 1977, 22, 106.

[12] Müller, V.; Karami, N.; Nyberg, L K.; Pichler, C.; Torche Pedreschi, P. C.; Quaderi, S.; Fritzsche, J.; Ambjörnsson, T.; Åhrén, C.; Westerlund, F. ACS Infect. Dis. 2016, 2, 322.

[13] Xu, L.; Cao, Z.; Ma, R.; Wang, Z.; Qin, Q.; Liu, E.; Su, B. Anal. Chem. 2019, 91, 12859.

[14] Sodhi, G. S.; Kaur, J. Forensic Sci. Int. 2001, 120, 172.
[15] Fung, T. C.; Grimwood, K.; Shimmon, R.; Spindler, X.; Maynard, P.; Lennard, C.; Roux, C. Forensic Sci. Int. 2011, 212, 143.

[16] Wargacki, S. P.; Lewis, L. A.; Dadmun, M. D. J. Forensic Sci. 2008, 53, 1138 .

[17] Oden, S.; Hofsten, B. V. Nature 1954, 173, 449

[18] Li, C.-Y.; Li, B.-Y.; Li, M.-G.; Geng, X.-P.; Wang, W. J. Chin. People's Pub. Sec. Univ. (Sci. Technol.) 2003, 8, 22 (in Chinese). (李重阳，李波阳，李敏刚，耿晓鹏，王伟，中国人民公安大学学 报(自然科学版), 2003, 8, 22.)

[19] Chen, Y.; Zhang, C.-J.; Gao, D.-M.; Yang, F.; Han, D.-X.; Niu, L. Chin. J. Appl. Chem. 2011, 28, 1099 (in Chinese). (陈艳, 张春静, 高东梅, 杨帆, 韩冬雪, 牛利, 应用化学, 2011, 28, 1099.)

[20] Xu, C.; Zhou, R.; He, W.; Wu, L.; Wu, P.; Hou, X. Anal. Chem. 2014, 86, 3279.

[21] Wu, P.; Xu, C.; Hou, X.; Xu, J.; Chen, H. Chem. Sci. 2015, 6, 4445.

[22] Ma, R.; Shimmon, R.; Mcdonagh, A.; Maynard, P.; Lennard, C.; Roux, C. Forensic Sci. Int. 2012, 217, e23.

[23] Li, Y.; Xu, L.; Su, B. Chem. Commun. 2012, 48, 4109

[24] Jin, X.; Dong, L.; Di, X.; Huang, H.; Liu, J.; Sun, X.; Zhang, X.; Zhu, H. RSC Adv. 2015, 5, 87306.

[25] Chen, H.; Chang, K.; Men, X.; Sun, K.; Fang, X.; Ma, C.; Zhao, Y.; Yin, S.; Qin, W.; Wu, C. ACS Appl. Mater. Interfaces 2015, 7, 14477.

[26] Lee, J.; Joullié, M. M. Tetrahedron Lett. 2015, 56, 3378.

[27] Xu, L.; Li, Y.; Wu, S.; Liu, X.; Su, B. Angew. Chem., Int. Ed. 2012, 124,8192 .

[28] Ma, R.-L.; Zhao, G.-H.; Piao, X.-J.; Chen, J. Forensic Sci. Technol. 2013, 38, 8 (in Chinese).

(马荣梁, 赵国辉, 朴相杰, 陈江, 刑事技术, 2013, 38, 8.)

[29] Zhou, X.-F.; Zhang, L.-Y. Forensic Sci. Technol. 2013, 38, 19 (in 
Chinese).

(周小凤, 张凌燕, 刑事技术, 2013, 38, 19.)

[30] Wei, Q.; Zhang, M.; Ogorevc, B.; Zhang, X. Analyst 2016, 141, 6172 .

[31] Wang, M.; Li, M.; Yu, A.; Zhu, Y.; Yang, M.; Mao, C. Adv. Funct. Mater. 2017, 27, 1606243.

[32] Christofidis, G.; Morrissey, J.; Birkett, J. W. J. Forensic Sci. 2018 , 63, 1616.

[33] Yan, L.; Yu, Y.-L. Forensic Sci. Technol. 2018, 43, 312 (in Chinese). (颜碟，喻彦林，刑事技术, 2018, 43, 312.)

[34] Wei, S.-Y.; Gong, X.; Ma, L.-Y.; Chen, J.-C.; Li, Q.-F.; Zhang, Z.-L. Bull. Chin. Ceramic Soc. 2019, 38, 2855 (in Chinese). (魏铄蕴，宫雪，马丽英，陈久存，李全芳，张子龙，硅酸盐通报， 2019, 38, 2855.)

[35] Du, Q.-Y.; Dong, L.-P.; Wu, X.-J.; Wang, J.-F.; Chang, J.; Zhang, Y.-F. Chem. Res. Appl. 2020, 32, 1 (in Chinese). (杜秋瑶, 董林沛, 吴小军, 王继芬, 常靖, 张云峰, 化学研究与 应用, 2020, 32, 1.)

[36] Jin, X.-D.; Wang, H.; Xu, S.; Lv, Y.-B.; Xu, T.-X.; Ma, R.-L. Forensic Sci. Technol. 2020, 45, 1 (in Chinese). (金晓东, 王浩, 徐升, 吕益标, 徐同祥, 马荣梁, 刑事技术, 2020, 45, 1.)

[37] Bécue, A. Anal. Methods 2016, 8, 7983.

[38] Fraser, J.; Deacon, P.; Bleay, S.; Bremner, D. H. Sci. Justice 2014, $54,133$.

[39] Sonnex, E.; Almond, M. J.; Bond, J. W. J. Forensic Sci. 2016, 61, 1100 .

[40] Bentolila, A.; Totre, J.; Zozulia, I.; Levin-Elad, M.; Domb, A J. Macromolecules 2013, 46, 4822.

[41] de Jong, R.; de Puit, M. Forensic Sci. Int. 2018, 291, 12.

[42] Pan, F.; Guo, W. J. Chin. People's Pub. Sec. Univ. (Sci. Technol.) 2014, 20, 5 (in Chinese). (潘飞, 郭威，中国人民公安大学学报(自然科学版), 2014, 20, 5.)

[43] Yuan, C.-J. Chin. J. Chem. Educ. 2019, 40, 13 (in Chinese). (袁传军, 化学教育, 2019, 40,13.)

[44] Friedman, M. J. Agric. Food Chem. 2004, 52, 385.

[45] Friedman, M.; David Williams, L. Bioorg. Chem. 1974, 3, 267.

[46] Hansen, D. B.; Joullié, M. M. Chem. Soc. Rev. 2005, 34, 408

[47] Jelly, R.; Lewis, S. W.; Lennard, C.; Lim, K. F.; Almog, J. Chem. Commun. 2008, 3513

[48] Hauze, D. B.; Petrovskaia, O.; Taylor, B.; Joullie, M. M.; Ramotowski, R.; Cantu, A. A. J. Forensic Sci. 1998, 43, 744.

[49] Grigg, R.; Mongkolaussavaratana, T.; Anthony Pounds, C.; Sivagnanam, S. Tetrahedron Lett. 1990, 31, 7215.

[50] Zhao, Y.-B.; Dang, G.-L.; Li, Z.-R.; Guo, W. Chem. Res. Appl. 2019, 31, 1401 (in Chinese)

(赵雅涁, 党刚利, 李卓容, 郭威, 化学研究与应用, 2019, 31, 1401.)

[51] Luo, J.; Xie, Z.; Lam, J. W. Y.; Cheng, L.; Chen, H.; Qiu, C.; Kwok, H. S.; Zhan, X.; Liu, Y.; Zhu, D.; Tang, B. Z. Chem. Commun. 2001, 1740

[52] Wan, W.; Tian, D.; Jing, Y.; Zhang, X.; Wu, W.; Ren, H.; Bao, H Angew. Chem., Int. Ed. 2018, 57, 15510.

[53] Jin, X.; Xin, R.; Wang, S.; Yin, W.; Xu, T.; Jiang, Y.; Ji, X.; Chen, L.; Liu, J. Sens. Actuators, B 2017, 244, 777.

[54] Pinto, A.; Svahn, N.; Lima, J. C.; Rodríguez, L. Dalton. Trans. 2017, 46, 11125.

[55] Tian, X.; Chen, L.; Li, Y.; Yang, C.; Nie, Y.; Zhou, C.; Wang, Y. J. Mater. Chem. C 2017, 5, 3669

[56] Zhao, G.-S.; Shi, C.-X.; Guo, Z.-Q.; Zhu, W.-H.; Zhu, S.-Q. Chin. J. Org. Chem. 2012, 32, 1620 (in Chinese) (赵国生, 史川兴, 郭志前, 朱为宏, 朱世琴, 有机化学, 2012,
32, 1620.)

[57] Yang, Y.; Li, S.; Zhang, Q.; Kuang, Y.; Qin, A.; Gao, M.; Li, F.; Tang, B. Z. J. Mater. Chem. B 2019, 7, 2434

[58] Xu, L.; Li, Y.; Li, S.; Hu, R.; Qin, A.; Tang, B. Z.; Su, B. Analyst $\mathbf{2 0 1 4}, 139,2332$

[59] Jin, X.; Wang, H.; Xin, R.; Ma, Y.; Wu, G.; Xu, T.; Xia, X.; Wang, S.; Ma, R. Analyst 2020, 145, 2311.

[60] Singh, P.; Singh, H.; Sharma, R.; Bhargava, G.; Kumar, S. J. Mater Chem. C 2016, 4, 11180.

[61] Singh, H.; Sharma, R.; Bhargava, G.; Kumar, S.; Singh, P. New J Chem. 2018, 42, 12900.

[62] Liu, R.; Song, Z.; Li, Y.; Li, Y.; Yao, W.; Sun, H.; Zhu, H. Sens. Actuators, $B$ 2018, 259, 840.

[63] Song, Z.; Liu, R.; Li, X.; Zhu, H.; Lu, Y.; Zhu, H. J. Mater. Chem. C 2018, 6, 10910 .

[64] Qiu, Z.; Hao, B.; Gu, X.; Wang, Z.; Xie, N.; Lam, J. W. Y.; Hao, H.; Tang, B. Z. Sci. China: Chem. 2018, 61, 966.

[65] Wang, Y.; Li, C.; Qu, H.; Fan, C.; Zhao, P.; Tian, R.; Zhu, M. J. Am. Chem. Soc. 2020, 142, 7497.

[66] Li, Y.; Sun, Y.; Deng, Y.; Liu, J.; Fu, J.; Ouyang, R.; Miao, Y. Sens. Actuators, B 2019, 283, 99 .

[67] Wang, S.; Liu, L.-B.; Lv, F.-T. Introduction to Nanomaterials, Chemistry Industry Press, Beijing, 2018, pp. 158 167 (in Chinese).

(王树，刘礼兵，吕凤婷，纳米生物材料，化学工业出版社，北 京, 2018, pp. 158 167.)

[68] Yu, J.; Rong, Y.; Kuo, C.; Zhou, X.; Chiu, D. T. Anal. Chem. 2016, 89,42

[69] Liou, S.; Ke, C.; Chen, J.; Luo, Y.; Kuo, S.; Chen, Y.; Fang, C.; Wu, C.; Chiang, C.; Chan, Y. ACS Macro Lett. 2016, 5, 154.

[70] Jiang, Y.; Li, J.; Zhen, X.; Xie, C.; Pu, K. Adv. Mater. 2018, 30, 1705980.

[71] Kim, D.; Lee, Y.; Jo, S.; Kim, S.; Lee, T. S. Sens. Actuators, B 2020, 307, 127641

[72] Wu, L.; Wu, I.; Dufort, C. C.; Carlson, M. A.; Wu, X.; Chen, L.; Kuo, C.; Qin, Y.; Yu, J.; Hingorani, S. R.; Chiu, D. T. J. Am. Chem. Soc. 2017, 139, 6911.

[73] Chen, L.; Wu, L.; Yu, J.; Kuo, C. T.; Jian, T.; Wu, I. C.; Rong, Y.; Chiu, D. T. Chem. Sci. 2017, 8, 7236.

[74] Chen, H.; Ma, R.; Fan, Z.; Chen, Y.; Wang, Z.; Fan, L. J. Colloid Interface Sci. 2018, 528, 200.

[75] Chen, H.; Ma, R.; Chen, Y.; Fan, L. ACS Appl. Mater. Interfacs 2017, 9, 4908

[76] Malik, A. H.; Kalita, A.; Iyer, P. K. ACS Appl. Mater. Interfacs 2017, 9, 37501.

[77] Wu, C.; Chiu, D. T. Angew. Chem., Int. Ed. 2013, 52, 3086.

[78] Lim, X. Nature 2016, 531, 26.

[79] Chen, Y. H.; Kuo, S. Y.; Tsai, W. K.; Ke, C. S.; Liao, C. H.; Chen, C. P.; Wang, Y. T.; Chen, H. W.; Chan, Y. H. Anal. Chem. 2016, 88, 11616

[80] Shin-Il Kim, B.; Jin, Y.; Uddin, M. A.; Sakaguchi, T.; Woo, H. Y.; Kwak, G. Chem. Commun. 2015, 51, 13634.

[81] Yoon, J.; Jin, Y.; Sakaguchi, T.; Kwak, G. ACS Appl. Mater. Interfaces 2016, 8, 24025

[82] Zhang, S.; Liu, R.; Cui, Q.; Yang, Y.; Cao, Q.; Xu, W.; Li, L. ACS Appl. Mater. Interfaces 2017, 9, 44134.

[83] Yang, Y.; Liu, R.; Cui, Q.; Xu, W.; Peng, R.; Wang, J.; Li, L. Colloids Surf., A 2019, 565, 118

[84] Wang, F.; Chen, J.; Zhou, H.; Li, W.; Zhang, Q.; Yu, C. Anal. Methods 2014, 6, 654 .

[85] Wang, K.; Yang, Z.; Li, X. Chem.-Eur. J. 2015, 21, 5680.

[86] Huang, H.; Zhou, Y.; Wang, M.; Zhang, J.; Cao, X.; Wang, S.; Cao, D.; Cui, C. Angew. Chem., Int. Ed. 2019, 58, 10132.

(Cheng, F.) 